NÚÑEZ, Raúl y VERA, Jaime, "Determinación judicial de la pena,

Motivación y su control en el Derecho penal de adolescentes chileno".

Polít. crim. Vol. 7, No 13 (Julio 2012), Art. 5, pp. 168 - 208.

[http://www.politicacriminal.cl/Vol_07/n_13/Vol7N13A5.pdf]

\title{
Determinación judicial de la pena, motivación y su control en el Derecho penal de adolescentes chileno*
}

\author{
Raúl Núñez Ojeda ** \\ Jaime Vera Vega ***
}

\section{Resumen}

El presente artículo aborda la garantía del deber de motivación de la sentencia en el ámbito de la responsabilidad penal de adolescentes infractores, conforme con el nuevo sistema instaurado por la Ley $\mathrm{N}^{\circ} 20.084$. En el mismo, se pretende ofrecer una mirada dogmática de las cuestiones relativas a la fundamentación de la sentencia penal condenatoria dictada conforme con las normas previstas en dicha ley, que posibilite superar la tradición jurídica imperante (especialmente la jurisprudencial), en cuanto a que este proceso de individualización de la pena escapa a las limitaciones dogmáticas por tratarse de una cuestión que el propio ordenamiento entrega a la discrecionalidad del sentenciador. Junto con ello, se plantea una formulación de la exégesis del sistema de determinación de la pena de adolescentes, así como de los criterios que lo rigen. Finalmente, se formula, a partir de la regulación del recurso de nulidad, eventuales paliativos a las infracciones de que la sentencia puede adolecer en materia de fundamentación de la pena en el Derecho Penal juvenil.

\section{Palabras clave}

Deber de motivación, determinación de la pena, sistema penal adolescentes, Derecho Penal y Derecho Procesal Penal.

\begin{abstract}
This article raises the question of the duty to provide justification for judgments in the field of juvenile criminal responsibility according to the new system established by Law $\mathrm{N}^{\circ}$ 20.084. The article tries to offer a dogmatic point of view regarding the issues related to the justification for convicting judgments passed under the provisions of Law $\mathrm{N}^{\mathrm{o}} 20.084$, in

\footnotetext{
* Este trabajo se enmarca dentro del proyecto FONDECYT regular $\mathrm{N}^{\circ} 1100901$, titulado "El proceso de determinación de la pena: estudio dogmático y crítico", cuyo investigador principal es el profesor Dr. Guillermo Oliver Calderón, de la Pontificia Universidad Católica de Valparaíso.

** Licenciado en Ciencias Jurídicas por la Universidad de Valparaíso (Chile); Doctor en Derecho por la Universidad Pompeu Fabra de Barcelona (España); Profesor Asociado de Derecho Procesal en la Pontificia Universidad Católica de Valparaíso (Chile).Correo electrónico: raul.nunez@ucv.cl

*** Licenciado en Ciencias Jurídicas por la Pontificia Universidad Católica de Valparaíso, Máster en Derecho Penal por las Universidades de Barcelona y Pompeu Fabra (España), Profesor de Derecho Penal en la Pontificia Universidad Católica de Valparaíso y en la Universidad Viña del Mar. Correo electrónico: jaime.vera@uvm.cl
} 
NÚÑEZ, Raúl y VERA, Jaime, "Determinación judicial de la pena,

Motivación y su control en el Derecho penal de adolescentes chileno".

order to overcome currently existing legal opinion (especially in case law) which sustains that the process of determination of the sentence escapes dogmatic control because it is a subject that purportedly the system entrusts to the court's discretion. The article also presents an exegesis of the system of determination of the sentence and of the criteria used to govern this system. Finally, based on the regulation of the recourse of nullity, possible measures to mitigate the errors that judgments may contain regarding the determination of the sentence in juvenile law are formulated.

\section{Key words}

Duty to provide justification for judgments, determination of the sentence, juvenile justice system, criminal law, criminal procedure law.

\section{Introducción.}

Un tema de gran sensibilidad para el usuario de la administración de justicia es, precisamente, el grado de control que un sistema procesal reconoce de las resoluciones dictadas por los funcionarios que integran los órganos que ejercen la función de adjudicación en un Estado de Derecho. En otras palabras, para la sociedad en su conjunto resulta importante saber hasta que punto se puede controlar el ámbito de discrecionalidad del órgano que ejerce la jurisdicción al decidir un caso determinado. ${ }^{1}$ Ciertamente, que hablamos de discrecionalidad, ya que en las hipótesis de arbitrariedad no se podría hablar en sentido estricto de decisión jurisdiccional, por ser un acto de puro voluntarismo del sujeto que actúa en nombre del Estado adjudicador. ${ }^{2}$

Lo antes señalado cobra aun mayor importancia en el campo de la individualización judicial de la pena. En efecto, mientras que hasta no hace mucho tiempo se admitían escasas limitaciones al arbitrio judicial ${ }^{3}$ para la determinación de la pena dentro del marco legal, la dogmática penal ha comenzado a plantear, de una manera cada vez más fuerte, la necesidad de fijar una plataforma teórica fuerte para la decisión en la que se selecciona la sanción punitiva a aplicar. En otras palabras, se presenta como desconcertante, para un observador del sistema penal, la gran preocupación de la ciencia punitiva por construir un sistema dogmático de alta precisión cuando se trata de establecer el si corresponde o no la aplicación de una consecuencia penal, entre otras razones, para evitar el arbitrio judicial,

\footnotetext{
${ }^{1}$ Para una visión de las reformas de los poderes judiciales de la Europa continental e insular confrontar con: BELL, John, Judiciaries within Europe. A Comparative Review, Cambridge: CUP, 2006, especialmente pp. 1 a 43.

${ }^{2}$ Aquí nos encontramos con los supuestos de responsabilidad del juez. Sobre el tema consultar en español, entre otros: MONTERO AROCA, Juan, Independencia y responsabilidad del juez, Madrid: Civitas, 1990, pp. 182 y ss.; DÍEZ-PICAZO GIMÉNEZ, Ignacio, Poder Judicial y responsabilidad. Madrid: La Ley, 1993, pp. 20 y ss.; y, DELGADO DEL RINCÓN, Luis Esteban, Constitución, Poder Judicial y responsabilidad, Madrid: Centro de Estudios Constitucionales, 2002, pp. 23 y ss.

${ }^{3}$ Como pone de manifiesto entre nosotros: MEDINA SCHULZ, Gonzalo, "Sobre la determinación de pena y el recurso de nulidad en la Ley 20.084 sobre responsabilidad penal adolescente", Revista de estudios de la justicia, $\mathrm{N}^{\circ} 11$ (2009), pp. 226 y ss.
} 
para luego, en el momento de determinar la calidad y cantidad de la sanción, considerar a ese arbitrio como un valor propio a la naturaleza de la mensuración de la pena. ${ }^{4}$

Así las cosas, dejar librado al ciudadano que se ha hecho acreedor de una sanción a una resolución que no exige una fundamentación teórica explícita, importa sostener que a partir del momento en que se ha acreditado que la conducta es "punible", el responsable penal queda sujeto (al menos dentro del marco penal) a la absoluta discrecionalidad de quien ha de decidir sobre su destino (el órgano de adjudicación del Estado). ${ }^{5}$

En el Derecho Penal de adolescentes la importancia es aún mayor que en el Derecho Penal de adultos. En efecto, mediante la Ley $\mathrm{N}^{\circ} 20.084$, Ley de Responsabilidad Penal de Adolescentes (en adelante LRPA), se ha establecido un nuevo régimen jurídico para el tratamiento de infracciones de ley penal por parte de adolescentes, esto es, menores de edad pero mayores de catorce años (art. $3^{\circ}$ LRPA). Elemento esencial del nuevo modelo, superador del esquema tutelar vigente en el país hasta la hace algunos años, es la afirmación sin ambages de una genuina responsabilidad penal de los adolescentes infractores. Por otra parte, y como la otra cara de la moneda, se establece un régimen punitivo diferenciado para los adolescentes, tanto en sus aspectos sustantivos como adjetivos, con garantías homologables a las que rigen para los infractores adultos y caracterizados por una relativa benignidad en comparación con el régimen penal general. ${ }^{6}$

La finalidad de este trabajo es realizar un estudio sobre el sistema de determinación judicial de la sanción aplicable en el marco de la LRPA, prestando especial atención a los criterios que fija el artículo 24 de la LRPA al órgano de adjudicación y el control que sobre aplicación de tales criterios se puede realizar a través del recurso de nulidad. Por cierto, el estudio abordará el problema desde el prisma de la garantía constitucional del deber de motivación de las resoluciones judiciales.

\section{La garantía constitucional del deber de motivación de las resoluciones judiciales.}

El sistema de garantías establecido por la Constitución Política de la República, como el contenido en los tratados internaciones, suscritos y ratificados por Chile, arman un entramado de garantías procesales que benefician al imputado. ${ }^{7}$ Efectivamente, el Estado como detentador legítimo del "ius puniendi", debe someter su poder de castigar al cause fijado por la Constitución y las leyes de procedimiento creadas por el Parlamento. ${ }^{8}$ El Estado en su tripe posición dentro del proceso penal (como Estado adjudicador -a través del juez del Poder Judicial-, como Estado persecutor -por medio del Ministerio Público-y como Estado defensor -a través de la Defensoría Penal Pública-) debe actuar sujeto a una

\footnotetext{
${ }^{4}$ ZIFFER, Patricia, “Consideraciones acerca de problemática de la individualización de la pena”, en: MAIER, Julio (Comp.), Determinación judicial de la pena, Buenos Aires: Editores del Puerto, 1993, pp. 89 y 90.

${ }^{5}$ ZIFFER, "Consideraciones", cit. nota n' 4, p. 90.

${ }^{6}$ HERNÁNDEZ BASUALTO, Héctor, "El nuevo Derecho penal de adolescentes y la necesaria revisión de su teoría del delito", Revista de Derecho, Universidad Austral, vol. XX, N² 2 (2007), p. 196.

${ }^{7}$ Un claro ejemplo de este modo de pensar en la dogmática alemana lo representa el trabajo del profesor: LAGODNY, Otto, Strafrecht vor den Schranken der Grundrecht, Tübingen: Mohr, 1996, passim.

${ }^{8}$ Una idea similar pero con una línea argumental diferente se puede ver en: KINDHÄUSER, Urs, Strafprozessrecht, Baden-Baden: Nomos, 2006, pp. 32 y ss.
} 
NÚÑEZ, Raúl y VERA, Jaime, "Determinación judicial de la pena,

Motivación y su control en el Derecho penal de adolescentes chileno”.

racionalidad encaminada al entendimiento (o no estratégica), ${ }^{9}$ de modo que el castigo que pueda resultar del enjuiciamiento sea visto como legítimo por los sujetos deliberativos que forman el sistema social (o sea que tenga una dimisión de legitimidad y no sea pura facticidad). ${ }^{10}$

Por otro lado, al ciudadano que se ve involucrado en el proceso penal como imputado no le es exigible que actúe con una racionalidad similar a la del Estado, titular de Derecho de castigar, sino que puede actuar con una racionalidad estratégica. Es más, en los sistemas continentales el imputado no sólo puede guardar silencio, sino que incluso, puede mentir, estando autorizado por el mismo Estado para actuar de esta manera. ${ }^{11}$

Dentro de este contexto se debe estudiar la garantía constitucional del deber de motivación de las resoluciones judiciales que pesa sobre el Estado adjudicador. ${ }^{12}$ En efecto, lo que se trata de "explicar" o "hacer comprender" es la razón de un acto de poder que afecta a derechos; es lo que confiere la necesidad de dar cuenta de su sentido una particular significación político-jurídica, con relevancia en el plano de la legitimidad. ${ }^{13}$

Desde una perspectiva histórica, la motivación de las sentencias se convierte en objeto de una obligación impuesta al juez por reglas generales a partir de 1790, es decir, a partir del momento en el que la legislación revolucionaria en Francia pone fin a los sistemas judiciales del ancien régime y pone los cimientos para la concepción moderna del proceso judicial y de la función del juez. En efecto, la ley francesa de 1790 es considerada de manera mayoritaria por la doctrina como el origen moderno de la obligación de motivar la sentencia, porque es principalmente en ella que se inspiran todas las codificaciones procesales posteriores en el resto de Europa. Así las cosas, en los códigos decimonónicos, y

\footnotetext{
9 Sobre el punto ver: HABERMAS, Jürgen, Theorie des kommunikativen Handelns, Band II, Frankfurt: Suhrkamp, 1981, pp. 7 y ss.

${ }^{10}$ Sobre el punto ver: HABERMAS, Jürgen, Faktizität und Geltung, Frankfurt: Suhrkamp, 1998, pp. 109 y ss., y, GÜNTHER, Klaus, Schuld und Kommunikative Freiheit, Frankfurt: Klostermann, 2005, pp. 245 y ss.

${ }^{11}$ Por todos ver: ROGALL, Klaus, Der Beschuldigte als Beweismittel gegen sich selbst, Berlin: Duncker und Humblot, 1977, especialmente pp. 67 y ss. y VERREL, Torsten, Die Selbsbelastungsfreiheit im Strafverfahren, München: CH. Beck, 2001, pp. 13 y ss. En inglés consultar: HELMHOLZ, RH.; GRAY, Charles M.; LANGBEIN, John H.; MOGLEN, Eben; SMITH, Henry E.; y, ALSCHULER, Albert W., The Privilege Against Self-Incrimination, Chicago: The University of Chicago Press, 1997, especialmente pp. 108 y ss.

${ }^{12}$ Monográficamente sobre la fundamentación de las sentencias, ver entre otros: IACOVIELLO, Francesco, La motivazione della sentenza peale e il suo controllo in cassazione, Milano: Giuffre, 1997, especialmente pp. 11 y ss.; COLOMER HERNÁNDEZ, Ignacio, La motivación de las sentencias: Sus exigencias constitucionales y legales, Valencia: Tirant lo Blanch, 2003, pp. 157 y ss.; IGARTUA SALAVERRIA, Juan, La motivación de las sentencias, imperativo constitucional, Madrid: Centro de Estudios Políticos y Constitucionales, 2003, pp. 19 y ss.; ITURRALDE SESMA, Victoria, Aplicación del Derecho y justificación de la decisión judicial, Valencia: Tirant lo Blanch, 2003, pp. 251 y ss.; RODRÍGUEZ BOENTE, Sonia Esperanza, La justificación de las decisiones judiciales, Universidad de Santiago de Compostela, 2003, pp. 199 y ss.; DÍAZ CANTÓN, Fernando, La motivación de la sentencia penal y otros estudios, Buenos Aires: Editores del Puerto, 2005 pp. 97 y ss.; DE ASÍS ROIG, Rafael, El Juez y la motivación en el Derecho, Madrid: Dykinson, 2005, pp. 77 y ss.; ALISTE SANTOS, Tomás-Javier, La motivación de las resoluciones judiciales, Madrid: Marcial Pons, 2011, pp. 33 y ss.; y, TARUFFO, Michele, La motivación de la sentencia civil, Madrid: Trotta, 2011, pp. 27 y ss.

${ }^{13}$ ANDRÉS IBÁÑEZ, Perfecto, Justicia penal, derechos y garantías, Lima: Palestra, 2007, p. 191.
} 
Polít. crim. Vol. 7, № 13 (Julio 2012), Art. 5, pp. 168 - 208.

[http://www.politicacriminal.cl/Vol_07/n_13/Vol7N13A5.pdf]

en consecuencia también en los del siglo XX, la obligación de motivación se convirtió en una constante, configurándose la misma como un requisito necesario de forma y contenido del pronunciamiento jurisdiccional. ${ }^{14}$

Con todo, en su origen se puede afirmar que los fines que perseguía la motivación se incardinan mejor con una concepción endoprocesal de la misma. Es decir, convencer a las partes sobre la justicia de la decisión, enseñarles el alcance de la sentencia y facilitar los recursos; y en lo que respecta a los tribunales que hayan de examinar los eventuales recursos presentados, la motivación de las sentencias les permite un control más cómodo. ${ }^{15}$

Frente a la concepción antes esbozada, en la actualidad se alza la concepción extraprocesal de la motivación. Para ella, la obligatoriedad de motivar, en tanto garantía constitucional, representa un principio jurídico político de controlabilidad; pero no se trata sólo de un control institucional (o jerárquico) sino de un control generalizado y difuso. Ni las partes, ni sus abogados, ni los jueces que examinan los recursos agotan el universo de los destinatarios de la motivación, ésta se dirige a los ciudadanos. En efecto, en un Estado democrático la soberanía reside en el pueblo, la actuación de la jurisdicción se convierten en expresión de un poder que el pueblo soberano ha delegado en los jueces y tribunales. En un una democracia constitucional, la obligación de motivar es un medio a través del cual los órganos de adjudicación rinden cuenta de sus decisiones a la fuente de la cual deriva su investidura. ${ }^{16}$

De lo antes señalado se deriva, como consecuencia lógica, la publicidad de la motivación y la inteligibilidad de la misma. También se debe agregar la nota de la autosuficiencia de la motivación, ya que para los ciudadanos la motivación es la única fuente de conocimiento y control sobre la decisión.

Respecto del sistema procesal penal, es Ferrajoli ${ }^{17}$ quien ha sostenido que la motivación es una garantía de cierre del sistema para el imputado. En efecto, el deber de motivación expresa y garantiza, la naturaleza cognoscitiva y no potestativa del juicio, vinculándolo en derecho a la estricta legalidad y de hecho a la prueba de la hipótesis acusatoria. Para este autor, la formulación pública de los motivos de los pronunciamientos judiciales protege a los imputados frente a la arbitrariedad judicial, ya que deja al descubierto al menos las afirmaciones que no pueden explicarse racionalmente. Así las cosas, la hipótesis acusatoria que, por medio de las pruebas, entra en debate con las afirmaciones refutatorias exteriorizadas por la defensa, exige que el órgano adjudicación divulgue los argumentos

\footnotetext{
${ }^{14}$ TARUFFO, Michele, "La motivación de la sentencia", Páginas sobre justicia civil, Madrid: Marcial Pons, 2009, p. 515. También ver TARUFFO, La motivación, cit. nota $\mathrm{n}^{\circ}$ 12, pp. 293 y ss.

${ }^{15}$ IGARTUA SALAVERRÍA, La motivación, cit. nota $\mathrm{n}^{\circ} 12$, pp. 21 y ss.; EL MISMO, El razonamiento en las resoluciones judiciales, Lima: Palestra, 2009, pp. 15 y ss. En el mismo sentido: COLOMER HERNÁNDEZ, La motivación de las sentencias, cit. nota $\mathrm{n}^{\circ}$ 12, pp. 123 y ss.; y, ALISTE SANTOS, La motivación de las resoluciones, cit. nota $\mathrm{n}^{\mathrm{o}} 12$, pp. 155 y ss.

${ }^{16}$ IGARTUA SALAVERRÍA, El razonamiento, cit. nota $\mathrm{n}^{\circ}$ 15, p. 15. También ver: TARUFFO, "La motivación de la sentencia", cit. nota $\mathrm{n}^{\mathrm{o}} 14$, pp. 516 y ss.

${ }^{17}$ FERRAJOLI, Luigi, Derecho y razón. Teoría del garantismo penal, Madrid: Trotta, 1995, pp. 622 y 623.
} 
NÚÑEZ, Raúl y VERA, Jaime, "Determinación judicial de la pena, Motivación y su control en el Derecho penal de adolescentes chileno".

por los cuales resulta razonable tener por probado los hechos sobre los cuales versa la acusación. ${ }^{18}$

La obligación de motivar las sentencias es un precepto recogido en muchas Constituciones, bien expresamente o bien implícito en la noción de debido proceso. En efecto, el deber que pesa sobre el Estado adjudicador de motivar las sentencias aparece consagrado de manera expresa en la propia Carta Magna de muchos Estados, como es el caso de la Constitución Política de Italia (art. 111) y de la Constitución Política de España (art. 120.3). ${ }^{19}$

En el ámbito del Derecho Internacional de los Derechos Humanos, se debe también destacar la jurisprudencia del Tribunal Europeo de Derechos Humanos, conforme con la cual el deber de motivar las sentencias proviene del artículo 6.1 del Convenio de Roma de 1950, que establece la garantía del debido proceso, de modo que las decisiones judiciales deben señalar de manera suficiente los motivos en los que se fundan. Según esta doctrina, el estándar que fija la garantía impone la motivación de toda sentencia, especialmente en los casos en los cuales se dispone contra ella un recurso, para lo cual es preciso que la decisión muestre que los argumentos más relevantes de las partes (derecho a ser oído) y que sus discusiones dirimentes (contradictorio) han sido tomadas en consideración por el tribunal, aunque ello no se refleje de manera tan detallada en las sentencias del mismo. ${ }^{20}$

Por otro lado, la Corte Interamericana de Derechos Humanos, siguiendo al Tribunal Europeo de Derechos Humanos, ha sostenido que, a partir de una invocación genérica al debido proceso, el deber de motivar las resoluciones judiciales es una garantía vinculada con la correcta administración de justicia, que protege el derecho de los ciudadanos a ser juzgados por razones que el derecho suministra, y otorga credibilidad de las decisiones jurídicas en el marco de una sociedad democrática. ${ }^{21}$ Por tanto, la motivación es para Corte Interamericana de Derechos Humanos una de las debidas garantías del debido proceso (Convención Americana de Derechos Humanos art. 8.1) con todas las consecuencias que de ello es necesario desprender. ${ }^{22}$

En Chile nuestra Constitución política no tiene una consagración expresa del deber de motivar las resoluciones por parte del órgano de adjudicación. Con todo, no parece dudoso

\footnotetext{
18 PASTOR, Daniel, "El deber judicial de motivar las condenas", en: VV.AA., Reflexiones sobre el procedimiento penal. Una tarde con Julio Maier", Buenos Aires: Ad Hoc, 2010, p. 55.

${ }^{19} \mathrm{El}$ profesor Maier acepta el deber legal de que los jueces profesionales deban motivar sus sentencias bajo amenaza de la invalidez de la misma. Por otro lado, critica las tesis doctrinales y jurisprudenciales que elevan este deber como garantía constitucional. Para este autor, estas tesis son invocaciones sintéticas y sin conexión argumental al orden republicano, al debido proceso y al derecho de defensa. Finalmente, Maier ve una amenaza en la garantía constitucional para el juicio por jurados (MAIER, Julio, Derecho procesal penal. Fundamentos, tomo I, Buenos Aires: Editores del puerto, 1996, pp. 481 y ss.).

${ }^{20}$ Sentencia "Hadjianastassius" del 16/12/1993, parágrafo 33. Siguen el mismo criterio: "Ruiz Torija" (1994), "Hiro Balani" (1994), "Higgins" (1998), "Maaouia" (1999), "Zoon" (2005), "Bochan" (2007), etc. Con todo, la antigua comisión estableció ciertas excepciones para los supuestos de enjuiciamiento por jurados.

${ }^{21}$ Sentencia "Apitz" de 5/8/2008, capítulo 5, párrs. 77 y ss. con cita del precedente de la misma Corte "Chaparro Álvarez", sentencia de 21/11/2007, párr. 107.

${ }^{22}$ PASTOR, "El deber judicial", cit. nota $n^{\circ} 18$, p. 59. Sobre el debido proceso penal en la jurisprudencia de la Corte Interamericana de Derechos Humanos ver por todos: TORO JUSTINIANO, Constanza María F., El debido proceso penal, Santiago: Ediciones Jurídicas de Santiago, 2009, pp. 63 y ss.
} 
Polít. crim. Vol. 7, № 13 (Julio 2012), Art. 5, pp. 168 - 208.

[http://www.politicacriminal.cl/Vol_07/n_13/Vol7N13A5.pdf]

que la misma es posible extraerla desde la noción de debido proceso consagrada en nuestra ley fundamental.

La inclusión de reglas procesales en actos normativos de carácter constitucional tiene en la tradición del derecho continental una existencia relativamente reciente. ${ }^{23}$ Efectivamente, el principio del due process of law se ha desarrollado en los ordenamientos anglosajones por más de siete siglos a través de una constante interpretación jurisprudencial y de una trascendente elaboración doctrinal, la que por primera vez fue formulada por escrito en el capítulo XXXIX de la Carta Magna de Inglaterra. ${ }^{24}$ En el ámbito de los Estados Unidos de América del Norte, la noción de debido proceso se introduce mor de la Enmienda V de la Constitución en 1791, planteando que los derechos fundamentales a la vida, la libertad y propiedad se garantizan a través del debido proceso. ${ }^{25}$

Como contrapartida, en el campo del derecho continental, las Constituciones europeas sólo después del término de la segunda guerra mundial establecieron con propiedad un Estado constitucional de Derecho, ${ }^{26}$ incorporando, entre otras cosas, específicas garantías procesales como derechos fundamentales de los ciudadanos. En el caso de Chile, la Constitución de 1980 estableció de una manera muy sucinta alguna de esas garantías procesales, pero con el restablecimiento de la democracia en 1990, se ha vivido un verdadero clima político hacia ese reconocimiento, lo que se ha traducido en una mayor concreción y profundización en dichas garantías. ${ }^{27}$

El fenómeno de constitucionalización del derecho no debe ser entendido desde una perspectiva estrictamente formal. Todo lo contrario, debe ser entendido como una opción cultural, un posicionamiento ideológico que busca consagrar de manera estable determinados principios (o ideas cardinales) del proceso que están destinadas a condicionar la credibilidad y la aceptabilidad de las formas de tutela jurisdiccional y las estructuras procesales. En otras palabras, en la base de la citada ideología se aprecia la idea que la justicia de la decisión final se encuentra necesariamente ligada a la justicia de la actividad procesal. Por otro lado, tampoco basta con la mera justicia procedimental, sino que hay que considerar también la justicia en la aplicación del derecho sustancial. Por tanto, entre estos dos extremos debe moverse la actuación de nuestros tribunales de justicia. ${ }^{28}$

En Chile, el debido proceso, al igual que el resto de los derechos fundamentales, goza de un reconocimiento constitucional. Nuestra Constitución Política se encarga de asegurar un

\footnotetext{
${ }^{23}$ COLOMBO CAMPBELL, Juan, El debido proceso constitucional, Ciudad de México: Porrúa, 2007, p. 19.

${ }^{24}$ En la misma se señala: "(...) ningún hombre libre podrá ser arrestado, detenido o preso, o desposeído de su propiedad, o de ninguna otra forma molestado, y no iremos en su busca no mandaremos prenderlo, salvo en virtud de enjuiciamiento legal de sus pares y por la ley de la tierra" (COLOMBO CAMPBELL, El debido proceso constitucional, cit. nota $\left.\mathrm{n}^{\circ} 23, \mathrm{p} .19\right)$.

${ }^{25}$ Sobre el punto ver: REDLICH, Norman; ATTANASIO, John; y, GOLDSTEIN, Joel K, Understanding Constitutional Law, New York: LexisNexis, 2005, pp. 275 y ss.

${ }^{26}$ FERRUA, Paolo, Il "giusto processo", Bologna: Zanichelli, 2005, pp. 15 y ss. Sobre el Estado de Derecho constitucional ver: HÄBERLE, Peter, La libertad fundamental en el Estado Constitucional, Granada: Comares, 2003, pp. 29 y ss.

27 BORDALÍ SALAMANCA, Andrés, "El debido proceso civil", La constitucionalización del derecho chileno, Santiago: Editorial Jurídica de Chile, 2003, pp. 251 y 252.

${ }^{28}$ En el mismo sentido: COMOGLIO, Luigi Paolo, Etica e técnica del "giusto processo", Torino: G. Giappichelli Editores, 2004, pp. 151 y ss.
} 
NÚÑEZ, Raúl y VERA, Jaime, "Determinación judicial de la pena, Motivación y su control en el Derecho penal de adolescentes chileno".

listado de derechos fundamentales a todas las personas, en su artículo 19. Es este artículo el que regula lo medular del debido proceso en su numeral tercero.

Es un error asociar el debido proceso en forma restringida al establecimiento del derecho a un "proceso previo legalmente tramitado y a las garantías de un procedimiento y una investigación racionales y justos", en los términos del inciso quinto del artículo $19 \mathrm{~N}^{\circ} 3$ de la Constitución. El debido proceso como principio de nuestro ordenamiento y derecho fundamental, es comprensivo de todas aquellas garantías que envuelven este numeral tercero, y aún más, de garantías presentes en otras disposiciones. Un completo estudio de la institución del debido proceso, también nos conduce al análisis de otras disposiciones constitucionales, tales como el artículo $19 \mathrm{~N}^{\mathrm{o}} 7$, que regula el derecho a la libertad personal y sus condiciones de privación o restricción. ${ }^{29}$

Con todo, la pregunta que surge es: ¿Qué hay tras esta fórmula de consagrar lo que la doctrina reconoce como el debido proceso en nuestra Constitución política? ${ }^{30}$ De la historia del precepto constitucional sabemos que no se quiso enumerar las garantías que debían entenderse incluidas en un procedimiento e investigación racional y justa. Se argumentaba, no sin algo de razón, que sería muy difícil, que podría fácilmente incurrirse en errores de extensión o de omisión, y que sería fuente de grandes conflictos el determinar qué garantías incluir y cuáles no. ${ }^{31}$ Sin embargo, no es esto lo que nos parece más interesante de destacar, sino la expresa intención de evitar la denominación genérica de debido proceso, ${ }^{32}$ "porque existe toda una historia anglosajona que la pueda complicar mucho más", ${ }^{33}$ aún más, se tenía el temor de "obligar al intérprete, a la jurisprudencia, a los tratadistas y a los abogados, a un estudio exhaustivo de los antecedentes, especialmente de la doctrina y la jurisprudencia anglosajona". ${ }^{34}$

\footnotetext{
${ }^{29}$ Aunque debemos reconocer que la opinión de la mayoría chilena de doctrina apunta en un sentido diverso.

${ }^{30}$ El contenido de la garantía constitucional del debido proceso es un tanto difusa. De acuerdo con Esparza Leibar, en España tanto la doctrina como la jurisprudencia se encontrarían divididas a la hora de determinar qué tanto debe abarcar el concepto del debido proceso; si tan sólo debe entenderse referido al conjunto de garantías señaladas en la segunda parte del artículo 24, si debe abarcar también el concepto más genérico y amplio del derecho a tutela judicial efectiva, o si por el contrario, debería entenderse por debido proceso un concepto amplísimo, que lo haga partícipe de la naturaleza jurídica de los principios generales del derecho. El mencionado autor se inclina por sostener la tercera noción de debido proceso, y de ese modo, éste no quedaría limitado a los términos del artículo 24 de la Constitución Española, sino que se abriría también a otras funciones, comprendiendo por ejemplo, el deber de motivación de las resoluciones contenido en el artículo 120.3 de dicha constitución, y por supuesto, lo dispuesto en el Convenio Europeo de Derechos Humanos sobre proceso equitativo. Lo interesante de esta postura es que expresamente se reconoce que el debido proceso sería una institución dinámica, y que abarcaría un número no taxativo de garantías (ESPARZA LEIBAR, Iñaki, El principio del proceso debido, Barcelona: JM. Bosch, 1995, pp. 168 y ss.).

${ }^{31}$ Para argumentos en este sentido, ver Actas Oficiales de la Comisión Constituyente, sesión $\mathrm{N}^{\circ} 101,9$ de Enero de 1975, p. 14.

${ }^{32}$ Como señala el profesor Tavolari Oliveros (TAVOLARI OLIVEROS, Raúl, "El proceso civil chileno: Una lectura desde el debido proceso y la eficacia de la jurisdicción, de cara a la reforma", en: EL MISMO, Tribunales, jurisdicción y proceso, Santiago: Editorial Jurídica de Chile, 1994, p. 49), la noción de debido proceso fue motivo de intensa preocupación de los redactores de la Constitución de 1980, quienes recelaron, empero, de utilizar los términos que la doctrina emplea pacíficamente, traduciendo la expresión due process of law.

${ }^{33}$ Declaraciones del comisionado señor Evans, en Actas Oficiales, cit. nota n ${ }^{\circ} 31$, (nota 31).

${ }^{34}$ Declaraciones del comisionado señor Evans, en Actas Oficiales, cit. nota n ${ }^{\circ} 31$, (nota 31).
} 
Polit. crim. Vol. 7, No 13 (Julio 2012), Art. 5, pp. 168 - 208.

[http://www.politicacriminal.cl/Vol_07/n_13/Vol7N13A5.pdf]

Por lo tanto, la Constitución exigiría tres condiciones copulativas para satisfacer el núcleo de la garantía del debido proceso: tramitación legal, racionalidad sustantiva y justicia. De acuerdo con Cea Egaña, serían estos dos últimos elementos las nociones claves para permitir la evolución del debido proceso a través de la jurisprudencia y. particularmente, mediante la inaplicabilidad por inconstitucionalidad. ${ }^{35}$ Concuerda en este punto López Masle, para quien:

"tan clara como la intención de que el contenido del procedimiento racional y justo fuera objeto de un desarrollo posterior de la jurisprudencia, fue la decisión de que ese desarrollo no se hiciera a través de un proceso de creación de reglas al modo de la jurisprudencia norteamericana, sino a través del control de reglas creadas legalmente, por la vía exclusiva del recurso de inaplicabilidad". ${ }^{36}$

En este orden de ideas, el Tribunal Constitucional chileno ha entendido que la motivación de la sentencia es connatural a la jurisdicción y fundamento indispensable para su ejercicio. Constituye,

"a la vez un deber del juzgador, un derecho para el justiciable. Es inherente al derecho a la acción y, por ende, a la concreción de la tutela judicial efectiva; elementos propios de las garantías del procedimiento racional y justo, cuya ausencia vulnera la exigencia constitucional y autoriza declarar la inaplicabilidad del precepto objetado". 37

A la misma conclusión se pude arribar desde otra perspectiva. En efecto, otro camino podría ser el peguntarnos por ¿Cuál es la función que realizan los jueces al resolver un caso dentro de un Estado democrático deliberativo? Sólo de esta manera podremos saber con precisión el contenido del acto de adjudicación.

Para nosotros la respuesta se construye a partir de la diferencia entre discurso de fundamentación (o justificación) y discurso de aplicación o adecuación, como formas discursivas complementarias. ${ }^{38}$ El primero, tiene por objeto justificar la validez o corrección de una norma, justificación que viene dada por el principio de universalidad. Aun cuando atendiendo al discurso de justificación o fundamentación una norma sea válida, ello no significa que esa norma deba ser automáticamente aplicada al caso concreto.

35 CEA EGAÑA, José Luis, Tratado de la Constitución del 1980. Características generales, garantías constitucionales, Santiago: Editorial Jurídica de Chile, 1988, p. 307.

36 LÓPEZ MASLE, Julián, "Debido Proceso en Chile: hacia un principio generador de reglas", en: BORDALÍ, Andrés (Coord.), Justicia Constitucional y Derechos Fundamentales, Universidad Austral de Chile, Santiago: Editorial LexisNexis, 2006, p. 191.

${ }^{37}$ Rol N ${ }^{\circ} 1373$, de 22 de junio de 2010, considerando 15.

${ }^{38}$ Aquí seguimos el pensamiento estructurado por Habermas y su discípulo Günther (GÜNTHER, Klaus, Der Sinn für Angemessenheit. Anwendungsdiskurse in Moral und Recht, Frankfurt: Suhrkamp Verlag, 1988, passim, y, HABERMAS, Faktizität und Geltung, cit. nota $\mathrm{n}^{\mathrm{o}} 10$, pp. 238 y ss.). Con todo, existe una opinión diversa del Profesor Alexy (ALEXY, Robert, Teoría de la argumentación jurídica, Madrid: Centro de Estudios Constitucionales, 1997, passim) que hacer referencia a la tesis del "caso especial". El citado autor sostiene que la pretensión de corrección también se plantea en el discurso jurídico; pero esta pretensión, a diferencia de los que ocurre en el discurso práctico general, no se refiere a que las proposiciones jurídicas en cuestión sean sin más racionales, sino sólo a que en el marco del ordenamiento jurídico vigente puedan ser racionalmente fundamentadas. 
NÚÑEZ, Raúl y VERA, Jaime, "Determinación judicial de la pena, Motivación y su control en el Derecho penal de adolescentes chileno".

Es aquí donde entra en juego el discurso de aplicación o adecuación: este discurso se refiere a la corrección de la decisión jurídica, en la cual hay que establecer si la norma prima facie aplicable es adecuada a una situación determinada, para lo que es necesario tener en cuenta todos los datos que caracterizan a esa situación, es decir, la situación de aplicación. La diferencia entre discurso de fundamentación y discurso de aplicación de las normas jurídicas reside en que el primero es un discurso práctico sobre la validez de las normas independientemente de la situación individual en la que serán aplicadas; mientras que el discurso de aplicación está centrado en la adecuación de las normas a las circunstancias relevantes del caso concreto (aspectos o circunstancias de hecho). ${ }^{39}$ Por tanto, fundamentación y aplicación son dos formas discursivas complementarias, la primera es labor del Poder Legislativo y la segunda es propiamente el discurso del órgano jurisdiccional.

También, se debe considerar que la decisión judicial debe ser una decisión doblemente limitada. ${ }^{40}$ Por un lado, por el principio de legalidad, que implica que el juez tiene que tomar la decisión aplicando el ordenamiento jurídico; en otras palabras, la decisión judicial tiene que ser una decisión legal. Por otro lado, como el ordenamiento no predetermina totalmente la solución a los casos individuales, hay un segundo límite a la decisión judicial, límite que viene dado por la correcta justificación de la misma, justificación que está en función de las razones dadas a favor de cada una de las opciones que se le plantean al juez en el proceso de aplicación. Por lo tanto, lo decisivo en la aplicación judicial del derecho no es sólo la aplicación de enunciados jurídicos (de fuentes del derecho) como fundamentos o razones para la decisión, sino también las razones dadas a favor de la aplicación de dichos enunciados frente a otros potencialmente aplicables, la determinación de un preciso significado de los mismos frente a otras interpretaciones, la consideración de determinados hechos como probados (alternativamente a las razones a favor de los mismos como no probados) y como encuadrables en una categoría jurídica (y no en otra), así como la elección de una correcta consecuencia jurídica dentro de las alternativas legales. ${ }^{41}$

De aquí surge, asimismo, la obligación de motivar las sentencias, obligación que no es sólo una exigencia de orden legal, sino que se deriva de la idea misma de la jurisdicción y de su ejercicio en los Estados democráticos, donde no pueden desligarse las ideas de jurisdicción y motivación: ésta es constitutiva de aquélla, de tal forma que la motivación no es algo obligatorio desde un punto de vista externo o formal, sino que es inherente a la aplicación de derecho.

En otras palabras, la fundamentación se compone en el hecho de juzgar y los motivos de la decisión. Aquí junto con los considerandos jurídicos se produce la valoración de la prueba. Las disposiciones relativas a procedimientos no norman, pues, ni las razones que deban considerarse admisibles, ni tampoco la marcha de la argumentación; pero aseguran ámbitos

\footnotetext{
${ }^{39}$ GÜNTHER, Der Sinn für Angemessenheit. Cit. nota $n^{\circ} 38$, passim; y, HABERMAS, Faktizität und Geltung, cit. nota $\mathrm{n}^{\circ} 10$, pp. 272 y ss.

${ }^{40}$ Sobre el problema de la interpretación me remito al escrito del discípulo del profesor Günther: BUNG, Jochen, Subsumtion und Interpretation, Baden-Baden: Nomos, 2003, pp. 9 y ss.

${ }^{41}$ GÜNTHER, Klaus, "Un concepto normativo de coherencia para una teoría de la argumentación jurídica", Doxa $\mathrm{N}^{\circ} 17-18$ (1995), pp. 274 y ss.
} 
Polít. crim. Vol. 7, № 13 (Julio 2012), Art. 5, pp. 168 - 208.

[http://www.politicacriminal.cl/Vol_07/n_13/Vol7N13A5.pdf]

para discursos jurídicos, que sólo en su resultado se convierte en objeto del procedimiento. Pues el resultado puede ser vuelto a examinar por las sucesivas etapas superiores.

\section{Motivación y determinación judicial de la pena.}

Junto a los poderes de denotación jurídica y verificación fáctica y sus expresiones en las dos formas de inferencia (inducción fáctica y deducción jurídica), ${ }^{42}$ la función de adjudicación reconoce otro tipo de poder, necesario para concluir la tercera inferencia (el llamado silogismo práctico) de que se compone el razonamiento judicial: el procedimiento de individualización de las consecuencias jurídicas. Además de aseverar la tesis de la comisión del delito por el sujeto culpable, el juez valora también, a los fines de la decisión sobre la medida o sobre la calidad de la pena, la gravedad específica del hecho en relación con el contexto ambiental en que se han verificado, con sus causas objetivas y sus motivos subjetivos, con la intencionalidad de la culpabilidad, en una palabra, con las circunstancias específicas con que el culpable ha actuado. ${ }^{43}$ Todo lo anterior conforma lo que Ferrajoli denomina equidad del juicio, en la que se expresa el poder de connotación. ${ }^{44}$

Para el autor antes mencionado, las tesis que describen estas circunstancias específicas, suelen ser aserciones dotadas de referencias empíricas, pero que es muy difícil predicar sobre ellas la existencia de una verdad jurídica. En efecto, la ley no prevé, ni podría prever todas las infinitas connotaciones particulares (que aumentan o atenúan la gravedad) de los hechos por ella denotados, sino que todo lo más puede indicar son sus criterios de valoración. ${ }^{45}$

Es posible que por las consideraciones anteriores ese poder haya sido tradicionalmente considerado como un poder discrecional del tribunal de mérito y, por ende, no revisable en casación, en la medida que se ejercite dentro de los límites legales. En otras palabras, la revisión de las sentencias judiciales en cuanto a la aplicación de las normas que regulan la determinación judicial de pena muestra que las Cortes suelen comprender las reglas de determinación de la sanción como un ejercicio de una potestad discrecional (absoluta) que impide su revisión por vía de recursos de derecho estricto. ${ }^{46}$ Con todo, sobre este punto se volverá más adelante al tratar el recurso de nulidad.

\footnotetext{
${ }^{42}$ Sobre el punto ver: NÚÑEZ OJEDA, Raúl, "El sistema de recursos procesales en el ámbito civil en un Estado democrático deliberativo", Ius et Praxis, $\mathrm{N}^{\circ} 1$, año 14 (2008), pp. 204 y ss.

${ }^{43}$ FERRAJOLI, Luigi, Derecho y razón, cit. nota $\mathrm{n}^{\circ} 17$, pp. 155 y 156 . También ver: DÍAZ CANTÓN, $L a$ motivación de la sentencia penal, cit. nota $\mathrm{n}^{\circ} 12, \mathrm{pp} .138$ y 139.

${ }^{44}$ FERRAJOLI, Derecho y razón, cit. nota n ${ }^{\circ} 17$, p. 156.

${ }^{45}$ FERRAJOLI, Derecho y razón, cit. nota no 17, p. 156.

46 Entre otro ver: RUDNIK VIZCARRA, Carolina, La compensación racional de circunstancias modificatorias en la determinación judicial de la pena, Santiago: Legal publishing, 2007, pp. 89 a 90; MEDINA SCHULZ, "Sobre la determinación de pena", cit. nota $\mathrm{n}^{\circ}$ 3, pp. 226 y 227; y, COUSO SALAS, Jaime, "Cometario al artículo 69", en: COUSO, J. y HERNÁNDEZ, H. (Dirs.), Código Penal comentado. Parte general. Doctrina y jurisprudencia, Santiago: Abelodo Perrot, 2011, pp. 617 y 618. Para la situación española ver por todos: DEMETRIO CRESPO, Eduardo, Prevención general e individualización judicial de la pena, Salamanca: Ediciones Universidad de Salamanca, 1999, pp. 271 y ss. Para la situación de Argentina ver: DÍAZ CANTÓN, La motivación de la sentencia penal, cit. nota $\mathrm{n}^{\circ}$ 12, pp. 139 y ss.
} 
NÚÑEZ, Raúl y VERA, Jaime, "Determinación judicial de la pena,

Motivación y su control en el Derecho penal de adolescentes chileno".

¿En cuánto al deber motivación de las sentencias, este alcanza a la individualización de las consecuencias jurídicas? La respuesta es definitivamente afirmativa. En efecto, la garantía constitucional del debido proceso impone al órgano de adjudicación la obligación de motivar las sentencias, cuestión que cubre al deber de fijar qué consecuencias jurídicas precisa ha de coronar la resolución del caso cuando el legislador le confía al tribunal esa tarea dejándole márgenes más o menos sustanciosos de actuación. ${ }^{47}$

Por cierto, que ello se presenta de manera muy clara en la doctrina penal nacional al comentar el artículo 69 del Código Penal. En efecto, como afirma Etcheberry, ${ }^{48}$ si bien el artículo 69 no fija una pauta rígida y precisa, es imperativo para el sentenciador, en el sentido de que debe consignar en su fallo la forma en que cumplió con lo prescrito por él.

Con todo, desde la entrada en vigencia del Código Procesal Penal la obligación se encuentra recogida en el artículo 342 del mismo cuerpo legal. En efecto, este artículo regula el deber de motivación de las sentencias que corresponde al órgano de adjudicación. La importancia de los requisitos c), d) y e) del artículo 342, que contienen el núcleo central de dicho deber, esto es, el razonamiento justificativo respecto de los hechos que se consideran probados o no probados, de su calificación jurídica y la decisión de absolución o condena, se manifiesta en que su omisión es causal de un motivo absoluto de nulidad del juicio y de la sentencia ${ }^{49}$. Para el tema que nos convoca, la letra d) del 342 deja claro que las cuestiones sobre determinación de la pena quedan cubiertas por el deber de motivación al señalar la necesidad de expresar las razones legales o doctrinales que sirven para calificar jurídicamente cada uno de los hechos y sus circunstancias y para fundar el fallo.

\section{Proceso de determinación de las penas en la LRPA.}

La Ley $\mathrm{N}^{0} 20.084$ estableció un sistema de responsabilidad de los adolescentes por infracciones a la ley penal. La dictación de esta normativa se enmarca en un proceso integral de "reforma al sistema de protección y justicia de la infancia", cuyo fin fue adecuar nuestro ordenamiento jurídico a la institucionalidad internacional que se prevé, especialmente, en la Convención Internacional sobre los Derechos del niño ${ }^{50}$ (en adelante CDN) y; además, la superación del antiguo sistema tutelar de responsabilidad penal, calificado de anacrónico y vulnerador de las garantías del menor. En esta dirección, se asume un proceso de reforma de la justicia de adolescentes, el cual apunta a la tendencia generalizada de los países de nuestro entorno cultural que han implementado procesos de reforma de esta naturaleza. ${ }^{51} 52$

\footnotetext{
${ }^{47}$ ANDRÉS IBAÑEZ, Justicia penal, cit. nota $\mathrm{n}^{\circ} 13$, pp. 203 y ss.

${ }^{48}$ ETCHEBERRY, Alfredo, Derecho Penal. Parte general (tomo II), Santiago: Editorial Jurídica de Chile, p. 191.

${ }^{49}$ HORVITZ LENNON, María Inés (con LÓPEZ MASLÉ, Julián), Derecho procesal penal chileno, tomo II, Santiago: Editorial Jurídica de Chile, 2004, p. 343.

${ }^{50}$ En este sentido, BERRÍOS DÍAZ, Gonzalo, "El nuevo sistema de justicia penal para adolescentes", Revista de estudios de la justicia, $\mathrm{N}^{\circ}$ 6, p. 161.

${ }^{51}$ Cfr. HIGUERA GUIMERÁ, Juan: Derecho penal juvenil, Barcelona: Editorial Bosch, 2003, p. 201.

${ }^{52}$ En efecto, antes de que en nuestro país se decidiera por la sustitución del régimen tutelar, a excepción de Argentina, México y Uruguay, todos los países de este entorno, con distintos matices, habían dictado normas encaminadas a la implementación de nuevos sistemas para regular la condición jurídico penal de la infancia y
} 
Este nuevo sistema parte de varias premisas consignadas en la CDN. La primera y más importante de todas: el interés superior del menor (art. 2). De este principio, a su vez, se deducen una serie de garantías, como el derecho que asiste al menor a una respuesta cualitativa y cuantitativamente diferente a la del adulto (arts. 47 y 40). Asimismo, el modelo parte de una idea básica, que consiste en el reconocimiento del adolescente como sujeto de derechos con capacidad para responder por sus actos. ${ }^{53}$ De ahí, que la Ley $\mathrm{N}^{\circ}$ 20.084 se caracterice por el establecimiento de un conjunto de "medidas" especiales, destinadas a hacer frente al fenómeno de la delincuencia juvenil de una manera diferenciada, en aras de satisfacer la doble finalidad que menciona su artículo 20: i) hacer efectiva la responsabilidad de los adolescentes por los hechos delictivos que cometan y, ii) que la sanción forme parte de una intervención socioeducativa amplia y orientada a la plena integración social.

Ante la escasez de normas que regulen materias relativas a la Teoría del Delito y cuestiones procesales en la LRPA, quizás su aspecto más destacado sea precisamente el establecimiento de un nuevo catálogo de sanciones y un complejo sistema de individualización de las mismas cuando se trata de delitos cometidos por adolescentes.

En cuanto al catálogo de sanciones, el artículo $6^{\circ}$ de la LRPA se encarga de enumerarlas en el siguiente orden: a) internación en régimen cerrado con programa de reinserción social; b) internación en régimen semicerrado con programa de reinserción social; c) libertad asistida especial; d) libertad asistida; e) prestación de servicios en beneficio de la comunidad; f) reparación del daño causado; multa y h) amonestación. Como penas accesorias se contemplan tanto la prohibición de conducir vehículos motorizados, como el tratamiento forzado de rehabilitación por adicción a las drogas y el alcohol del artículo $7^{\circ}$ LRPA. Como se puede apreciar se trata de un catálogo bastante diverso, , aunque debiese permitir al juez responder de modo proporcionado y eficiente a las distintas expresiones que pueden presentar los ilícitos cometidos adolescentes. ${ }^{54}$

El nuevo sistema, ha sido caracterizado por Horvitz, como de carácter legal, dependiente del existente en el Código Penal, con un marco bastante extenso de individualización judicial, mucho más amplio que el previsto en el Código Penal para delitos cometidos por adultos. ${ }^{55}$ Es precisamente el amplio espacio que deja entregado al juez en la determinación de la pena, la característica que lo acerca más a los sistemas de criterios generales, aspecto

la adolescencia. Cfr. BELOFF, Mary, "Algunas confusiones en torno a las consecuencias jurídicas de la conducta transgresora de la ley penal en los nuevos sistemas de justicia juvenil latinoamericanos", en: GARCÍA MENDEZ, Emilio (Comp.), Adolescentes y responsabilidad penal, Buenos Aires: Ad Hoc, 2001, p. 36.

${ }_{53}^{53}$ En esta misma línea, de acuerdo con Cillero, las leyes sobre responsabilidad de los adolescentes infractores de la ley penal, surgen como un sistema centrado en el sujeto, que se estructura a partir de una nueva concepción de los niños y adolescentes, derivada directamente de la CDN. Cfr. CILLERO BRUÑOL, Miguel, "Nulla poena sine culpa. Un límite necesario al castigo penal de los adolescentes", en: GARCÍA MENDEZ, Emilio (Comp.), Adolescentes y responsabilidad penal, Buenos Aires: Ad Hoc, 2001, p. 74.

${ }_{55}^{54}$ En este sentido, MEDINA SCHULZ, "Sobre la determinación de pena", cit. nota no 3, pp. 212 y 213.

${ }^{55}$ HORVITZ LENNON, María Inés, "Determinación de las sanciones en la ley responsabilidad penal juvenil y procedimiento aplicable", Revista de estudios de la justicia, № 7 (2006), p. 102. 
NÚÑEZ, Raúl y VERA, Jaime, "Determinación judicial de la pena, Motivación y su control en el Derecho penal de adolescentes chileno".

desde donde se extrae la importancia que tiene la fundamentación de la sentencia en este ámbito.

La principal diferencia que es posible advertir entre el sistema de adultos y de adolescente, dice relación con el orden de las distintas fases del proceso. Así, mientras en el caso de los adultos, el proceso de determinación de la pena implica establecer, primero, la naturaleza de la sanción (título de castigo, marco penal) y, en segundo lugar, la cuantía de la sanción (ponderación de las etapas de desarrollo del delito, ponderación de las formas de intervención en el hecho, ponderación de las circunstancias modificatorias y fijación de la cuantía exacta de la pena). En el caso de los adolescentes se utiliza un orden inverso: se determina primero la cuantía de la sanción y luego su naturaleza.

De acuerdo con lo afirmado, en el sistema que prevé la LRPA es posible distinguir cuatro etapas: a) Determinación del título de castigo; b) determinación del marco penal; c) determinación de la duración de la pena; d) determinación de la naturaleza de la pena.

\subsection{Determinación del título de castigo:}

Para la determinación del título de castigo se debe proceder exactamente igual que en el caso de los adultos, distinguiendo según si no encontramos frente a un caso de unidad de título de castigo (delito simple, delito complejo, delito continuado o concurso aparente de leyes penales) o bien frente a un caso de pluralidad de títulos de castigo (concurso real de delitos, concurso ideal de delitos).

\subsection{Determinación del marco penal:}

La norma fundamental para la determinación del marco penal se encuentra establecida en el artículo 21 LRPA, que señala: "se entenderá que la pena asignada al delito cometido por un adolescente es la inferior en un grado al mínimo de los señalados por la ley para el ilícito correspondiente". El sentido de esta norma, es hacer operativa la garantía prevista en la $\mathrm{CDN}$, en orden a que al adolescente le corresponde una pena cuantitativamente inferior a la de los adultos.

Este artículo 21, fue objeto de una modificación posterior a la promulgación de la LRPA, por la Ley $\mathrm{N}^{\circ}$ 20.191. La misma, pretendió despejar algunas dudas que surgieron del texto original, respecto de cuál era marco penal abstracto aplicable a los adolescentes. Del antiguo texto contenido en el artículo 22, se podía colegir que el marco penal abstracto contemplado en el nuevo sistema, era el correspondiente a los adultos, más la rebaja en un grado. Este entendimiento de la norma generaba problemas, por ejemplo, en la definición del concepto de crímenes, simples delitos y faltas para adolescentes, pues si se consideraba que el antiguo artículo 22 contenía un marco penal abstracto, de ello resultaba que todos los tipos penales, previstos en el Código Penal o en leyes especiales, que dentro de su régimen penal contemplaban como sanción mínima penas mayores en su grado mínimo, en el estatuto de adolescentes aplicada la rebaja, debían ser considerados como simples delitos. Lo anterior, a su vez, traía aparejado otras consecuencias, como la improcedencia de la medida de internación provisoria para hechos que contenían el marco penal mencionado, 
Polít. crim. Vol. 7, № 13 (Julio 2012), Art. 5, pp. 168 - 208.

[http://www.politicacriminal.cl/Vol_07/n_13/Vol7N13A5.pdf]

atendida la restricción de esta medida sólo para hechos que merezcan la calificación de crímenes (artículo 33 LRPA).

Con la implementación de esta reforma, se despejaron estas dudas, pero de ello, resultó otra consecuencia del más alto interés: el marco penal de adolescentes, nunca está integrado por penas indivisibles, ni por más de un grado de una pena divisible, pues siempre consistirá un grado de una pena divisible o la mitad (superior o inferior) de un grado de una pena divisible. $^{56}$

\subsection{Determinación de la duración de la pena:}

Respecto de esta fase del proceso, el mismo artículo 21, inciso 2 de la LRPA, indica: "Para establecer la duración de la sanción que deba imponerse con arreglo a la presente ley, el tribunal deberá aplicar, a partir de la pena inferior en un grado al mínimo de los señalados por la ley para el ilícito correspondiente, las reglas previstas en el Párrafo 4 del Título III del Libro I del Código Penal, con excepción de lo dispuesto en el artículo 69 de dicho Código" (artículos 50 a $78 \mathrm{CP}$ ). En otras palabras, en este es el momento el tribunal debe efectuar la ponderación legal de delito (etapas de desarrollo y forma de intervención del sujeto) y de las circunstancias modificatorias de responsabilidad que concurrieren.

Al igual que ocurre en el proceso de adultos, las distintas decisiones que se adopten en esta segunda fase del sistema, involucran la adopción de medidas que deben ser objeto de ejercicios argumentativos y de fundamentación, los cuales deben ser explicitados en el fallo.

Según cierto sector de la doctrina, la remisión que este artículo hace a las reglas generales de determinación de la pena, supone una aplicación absoluta, imperativa, preferente y sin excepciones de las reglas de proporcionalidad contenidas en los artículos 51 y 52 del Código Penal, lo que ha supuesto la derogación, por norma posterior y especial, del artículo 450 inciso 1 del mismo cuerpo legal y otras análogas.$^{57}$ Esta postura es coherente con lo establecido en el artículo 2 inciso 2, en cuanto a que todas las decisiones que se adopten respecto de la situación del menor, se deben considerar los derechos y garantías consagrados en la Constitución, la ley y los demás instrumentos internacionales ratificados por Chile y que se encuentren vigentes. Entre estos últimos, se encuentra la CDN, que en su artículo 40.4 consagra la garantía de la proporcionalidad de la pena, que es incompatible con normas como la prevista en el artículo 450 inciso 1 del Código Penal. ${ }^{58}$

\footnotetext{
${ }^{56}$ En este mismo sentido, MATUS ACUÑA, Jean Pierre, "Proposiciones respecto de las cuestiones no resueltas por la Ley $\mathrm{N}^{\circ} 20.084$ en materia de acumulación y orden de cumplimento de las penas", Revista Ius et Praxis, Vol. 14, № 2 (2008), p. 546.

${ }^{57}$ CERDA, Mónica y CERDA, Rodrigo, Sistema de responsabilidad penal para adolescentes, Santiago: Librotecnia, 2006, p. 86.

58 Manifiesta una opinión distinta Matus, para quien el hecho que el artículo 22 no haya excluido expresamente de su remisión al artículo 55 del Código Penal hace insostenible esta postura. Cfr. MATUS ACUÑA, "Proposiciones respecto de las cuestiones", cit. nota ${ }^{\circ}$ 56, p. 546. Sin embargo, lo que este autor no considera es que frente al conflicto de normas, se debe preferir aquella interpretación que maximice las garantías del menor.
} 
NÚÑEZ, Raúl y VERA, Jaime, "Determinación judicial de la pena,

Motivación y su control en el Derecho penal de adolescentes chileno".

Luego de aplicación de esta regla, el artículo 22 de la LRPA, establece un límite a la extensión que resulte de la aplicación de la misma, pues cuando ella exceda de los máximos señalados por el artículo 18 para la privación de libertad: 5 años, para los menores de dieciséis años y 10 años, para los mayores de esa edad, se debe que ajustar la extensión a esos máximos. En consecuencia, y aunque no existan circunstancias atenuantes de responsabilidad criminal que permitan rebajar la pena en un grado, dicha rebaja debe operar de pleno derecho por la sola circunstancia de la edad del menor. La aplicación de este límite máximo, ha generado otro problema interpretativo, a propósito de los supuestos de concursos materiales de delitos, pues no existe claridad en orden a si debe entenderse como un límite máximo de la pena total correspondiente al concurso, o bien como un mero límite singular a cada pena individualmente considerada. A nuestro juicio, la primera es la solución correcta. Ello se ve, además, apoyado por un argumento de texto: el artículo 22 de la LRPA, regla que impone como extensión máxima para la sanción los plazos del artículo. 18 , se aplica después de que se aplicaron -por disposición del inciso $2^{\circ}$ del mismo artículo 21 las reglas sobre los concursos de delitos (incluidas en el párrafo $4^{\circ}$, Título III, del Libro I del Código Penal); así, los concursos se resuelven primero (artículo 21, inciso 2), y después, sobre ese resultado, se impone el límite máximo a la privación de libertad (artículo 22), que por lo demás es expresión de una garantía fundamental de la CDN prevista en su artículo 37 , letra b). ${ }^{59}$

Por su parte, existen reglas especiales que establecen máximos para la duración de otras sanciones, las cuales tienen preferencia por sobre la extensión que resulte de la aplicación de las reglas anteriores: así sucede con el máximo de tres años para la libertad asistida y para la libertad asistida especial, o para los servicios en beneficio de la comunidad, que se extenderán por un máximo de 120 horas, distribuidas de la forma más conveniente para el cumplimiento de los fines tenidos en cuenta al escoger tal sanción.

Sin perjuicio de lo anterior, a nuestro juicio, el criterio fundamental que debe definir la extensión de las medidas, es el interés superior del menor a que se refieren los artículos 3.1 de la CDN, y el artículo 2 de la LRPA. Estas normas señalan que dicho interés se debe tener en consideración en todas las actuaciones judiciales o administrativas relativas a los procedimientos, sanciones y medidas aplicables a los adolescentes infractores de la ley penal. Una de las interpretaciones posibles de este concepto jurídico indeterminado, consiste en vincularlo con el principio de prohibición de exceso o proporcionalidad en sentido amplio, de modo que las medidas que se adopten de entre las previstas en la ley, deben ser adecuadas al fin perseguido, que no es otro que la protección de bienes jurídicos en interés del menor. ${ }^{60}{ }^{61}$ Este criterio, además, se especifica en la fase siguiente, por la relación que sin duda tiene con el criterio de la idoneidad de la letra f) del artículo 24.

\footnotetext{
${ }^{59}$ En este mismo sentido, MATUS ACUÑA, "Proposiciones respecto de las cuestiones", cit. nota $\mathrm{n}^{\mathrm{o}} 56, \mathrm{p}$. 547; CERDA/CERDA, Sistema de responsabilidad penal para adolescentes, cit. nota n ${ }^{\circ}$ 57, p. 87.

${ }^{60}$ En este sentido, GONZÁLEZ CUSSAC y CUERDA ARNAU, "Derecho Penal de menores: criterios generales de aplicación de las medidas", en: GONZÁLEZ CUSSAC/TAMARIT SUMALLA/GÓMEZ COLOMER (Coords.), Justicia penal de menores y jóvenes, Valencia: Tirant lo Blanch, 2002, pp. 101 y 102. Nótese que esta interpretación del criterio no involucra en caso alguno, revivir la idea característica del sistema tutelar, en cuanto a que las medidas se imponen para la protección del menor. Concordamos con estos autores, respecto a que es necesario desterrar la confusa, perturbadora y peligrosa concepción de las medidas como instrumentos destinados a la tutela del menor, por cuanto la desvinculación de las mismas con el
} 
Por su parte, desempeña un rol de cierre en esta fase el principio de privación de libertad como último recurso. En efecto, a partir del principio establecido en el artículo. 37, letra b), de la CDN, el artículo 26, inciso primero, de la LRPA, establece, dentro del párrafo correspondiente a la determinación de las sanciones, que: "La privación de libertad se utilizará sólo como medida de último recurso". El artículo 47 de la misma LRPA reitera tal regla, enfatizando el carácter excepcional de estas sanciones. Además, de acuerdo con el citado Art. 37, letra b), de la $\mathrm{CDN}$, esta medida no sólo es un último recurso, sino que, además, se utilizará; "durante el período más breve que proceda".

Como una forma de hacer operativa esta garantía, el inciso final del artículo 26 LRPA estipula que: "en ningún caso se podrá imponer una pena privativa de libertad si un adulto condenado por el mismo hecho no debiere cumplir una sanción de dicha naturaleza". En cuanto al sentido de esta norma, la doctrina y jurisprudencia nacional han sido vacilantes. Una primera posibilidad interpretativa, postula que la misma impide la aplicación cuando existen partícipes adultos y menores sancionados por el mismo hecho, y no se condena a una privativa de libertad al adulto. ${ }^{62}$ Desde luego, esta visión restringida de la garantía no se condice con su espíritu, junto con conducir a soluciones contradictorias. Así por ejemplo, si en un mismo hecho intervinieran como participes adultos y menores de edad y estos últimos fueran multireincidentes y el (o los) adulto (s) fuera un sujeto sin antecedentes penales, de modo que pudiese acceder a beneficios alternativos de la Ley $\mathrm{N}^{\circ} 18.216$, el (o los) menor (es), no podrían ser castigados con una pena privativa de la libertad, porque en el mismo hecho no correspondería sancionar de esa forma al (los) adultos. Viceversa, si el adulto fuera un multireincidente, no cabría aplicar esta limitante respecto del menor, pues el

principio de exclusiva protección de bienes jurídicos, trae aparejado el riesgo de justificar su imposición en la corrección del carácter, en la conducción o forma de vida o simplemente en el hecho de castigar a los menores antisociales.

${ }^{61}$ Otra posible definición de este concepto es la postulada en nuestra doctrina por Cillero. Según este autor, desde la ratificación de la Convención existe una absoluta equivalencia entre el contenido del interés superior del niño y los derechos fundamentales del niño reconocidos en el Estado de que se trate. De este modo, es posible afirmar que el interés superior del niño es la satisfacción integral de sus derechos. Además, agrega que la formulación del principio en el artículo tercero de la $\mathrm{CDN}$, permite desprender las siguientes características: es una garantía, ya que toda decisión que concierna al niño debe considerar primordialmente sus derechos; es de una gran amplitud, ya que no sólo obliga al legislador, sino también a todas las autoridades e instituciones públicas y privadas y a los padres; también es una norma de interpretación y/o de resolución de conflictos jurídicos; finalmente, es una orientación o directriz política para la formulación de políticas públicas para la infancia, permitiendo orientar las actuaciones públicas hacia el desarrollo armónico de los derechos de todas las personas, niños y adultos, contribuyendo, sin dudas, al perfeccionamiento de la vida democrática". Cfr. CILLERO BRUÑOL, Miguel, "El interés superior del niño en el marco de la Convención sobre los Derechos del Niño”, en: http://www.observatoriosocial.com.ar/proyectos/proelinteres.pdf, [última visita 13.03.12]. A nuestro juicio, esta interpretación también sirve para definir el rol del principio del interés superior del niño en el sistema de determinación de la extensión de las medidas de la LRPA, pues la idea de plena satisfacción de los derechos del menor puede ser vinculada, entre otras materias, con los principios de igualdad y la proporcionalidad de las medidas, desde el punto de vista de sus fines.

${ }^{62}$ Se refiere a esta posibilidad interpretativa, Medina quien de todos modos reconoce que su extensión no es clara, agregando que dado el carácter extraordinario de la privación de libertad para menores parece ser irrelevante que al adulto se le sancione por un grado menor de participación en el hecho y al menor como autor, de modo que la regla del artículo 26 LRPA sería preferente y excluiría de todos modos la aplicación de una pena privativa de libertad, bastando acreditar la identidad del hecho atribuido a los distintos partícipes. MEDINA SCHULZ, "Sobre la determinación de pena", cit. nota nº 3, pp. 213 y 214. 
NÚÑEZ, Raúl y VERA, Jaime, "Determinación judicial de la pena,

Motivación y su control en el Derecho penal de adolescentes chileno".

adulto debiese cumplir una pena privativa de libertad en cualquier caso, lo que carece también de sentido. Es por ello que resulta más adecuado el sentido atribuido a esta limitación por Horvitz, para quien la misma involucra que bajo ningún supuesto podrá aplicarse judicialmente al adolescente la pena de internación en régimen cerrado o semicerrado de privación de libertad, cuando la pena aplicable no supere los cinco años de duración y este cumpla con los requisitos exigidos por la Ley $\mathrm{N}^{\circ} 18.216$ para poder acceder a alguna de las medidas alternativas que dicho cuerpo legal contempla. ${ }^{63}$ Es decir, no se trata de la comparación entre un adulto y un menor en un caso concreto, sino que se debe cotejar la situación del menor enjuiciado, en abstracto, con la de un delito en ese mismo supuesto.

\subsection{Determinación de la naturaleza de la sanción:}

Para determinar la naturaleza de la pena, es necesario ubicar la duración establecida en la etapa anterior en alguno de los tramos que prevé el artículo 23 LRPA. Cada uno de esos tramos señala las alternativas de pena, que en atención a su naturaleza, puede aplicar el tribunal.

También se permite que al dictar sentencia, el juez disponga la suspensión de la pena por seis meses (artículo 41), cuando se trate de una sanción privativa o restrictiva de libertad igual o inferior a 540 días y existan antecedentes favorables que hagan desaconsejable su imposición. Transcurrido el plazo y sin que el imputado haya sido objeto de nuevo requerimiento o de una formalización de la investigación, se deja sin efecto la sentencia.

Según el artículo 24 LRPA, los criterios que deben utilizarse para elegir la naturaleza de la pena son:

a) gravedad del ilícito de que se trate;

b) calidad en que el adolescente participó en el hecho y el grado de ejecución de la infracción;

c) atenuantes o agravantes de la responsabilidad;

d) edad del adolescente infractor;

e) extensión del mal causado por el delito, y

f) idoneidad de la sanción para fortalecer el respeto del adolescente por los derechos y libertades de las personas y sus necesidades de desarrollo e integración social

Tratándose de la pena de multa, además de los criterios del artículo 24 LRPA, deberán considerarse "la condición y las facultades económicas del infractor y de la persona a cuyo cuidado se encontrare" (artículo 9 inciso $1^{\circ}$ LRPA).

Atendida la importancia que cada uno de ellos tiene en la fundamentación de la pena, le asignaremos un apartado especial en que nos dedicaremos a precisar cuál es el sentido que corresponde atribuir a cada uno de ellos.

${ }^{63}$ HORVITZ LENNON, “Determinación de las sanciones", cit. nota no ${ }^{\circ} 55$, p. 110. 
Polít. crim. Vol. 7, № 13 (Julio 2012), Art. 5, pp. 168 - 208.

[http://www.politicacriminal.cl/Vol_07/n_13/Vol7N13A5.pdf]

\section{Los criterios del artículo 24 de la LRPA.}

Según mencionábamos en el apartado anterior, la determinación de la naturaleza de la sanción a aplicar, está sujeta a una serie de baremos o criterios que prevé el artículo 24 de la LRPA. Nótese que la precisión acerca del real sentido y alcance de estos criterios, resulta de vital importancia en la labor de fundamentación de la sentencia que establece la responsabilidad penal del menor, al extremo que la propia ley se hace cargo de ello, al señalar explícitamente que: "Para determinar la naturaleza de las sanciones, dentro de los márgenes antes establecidos, el tribunal deberá atender, dejando constancia de ello en su fallo, a los siguientes criterios: (...)".

Antes de referirnos al contenido de cada uno de ellos, nos parece necesario abordar algunas cuestiones previas. La primera de ellas, supone determinar si se trata de un catálogo cerrado de consideraciones admisibles en la definición de la naturaleza de la pena o no. Respecto de esta cuestión, si bien en virtud de la plena vigencia del principio de legalidad, se debiese concluir que se trata de criterios taxativos y únicos, de modo que no cabe al operador jurídico la creación de otros nuevos, mediante el recurso a la analogía, no es menos cierto que constituyen factores de una extensión bastante amplia a la hora de suministrar el ámbito material al que el tribunal debe dirigir su atención. Lo anterior resulta especialmente práctico, pues permite compatibilizar las exigencias de certeza que impone el mencionado principio, con un cierto grado de flexibilidad que debe predominar en el proceso de individualización de la pena, más aún, cuando se trata de determinar la pena que se va a imponer a adolescentes, respecto de quienes por imperativo legal, deben primar consideraciones vinculadas con su reinserción social (artículo 20 LRPA).

En segundo término, se debe resolver si se trata, o no, de criterios ambivalentes, esto es, que en el caso concreto pueden operar a favor o en contra del autor. Sobre esta cuestión se ha abierto un interesante debate en nuestra doctrina, la cual, vincula esta materia con el principio non bis in ídem y ha dado origen a dos visiones antitéticas.

De acuerdo con una primera postura, sostenida por Horvitz, al haberse contemplado los mismos factores en dos fases distintas de determinación de la pena (primero, para fijar su extensión; después, para fijar su naturaleza), se infringe el principio de no doble valoración. Así, por ejemplo, expresa, que los factores y circunstancias modificatorias de la responsabilidad penal juvenil operan en dos niveles: primero, en la fijación de la extensión o duración de la sanción (artículo 22 LRPA) y, también, en la selección de la sanción aplicable dentro del marco penal determinado temporalmente (artículo 24 LRPA). En su criterio, esta situación podría determinar, prima facie, una doble consideración del mismo hecho o circunstancia para la cuantificación de la sanción, procedimiento que se encuentra terminantemente proscrito en el caso de las circunstancias que agravan la responsabilidad penal, por imperativo del principio non bis in idem, que encuentra cobertura legal en el artículo 63 del Código Penal. Finalmente, agrega, que esto ocurrirá normalmente cuando los criterios de determinación de la naturaleza de la pena ya hayan sido considerados para 
NÚÑEZ, Raúl y VERA, Jaime, "Determinación judicial de la pena, Motivación y su control en el Derecho penal de adolescentes chileno".

fijar la gravedad del delito y la posición o lugar de la consecuencia asignada al mismo dentro de la escala de penas. ${ }^{64}$

Un segundo planteamiento, sostenido más recientemente por Medina, postula que la supuesta infracción del principio non bis in ídem en la fase de determinación de la naturaleza de la sanción de adolescentes es una cuestión que requiere de ulteriores precisiones. En este sentido, critica la postura anterior en tanto se estructura sobre un presupuesto cuestionable, esto es, el hecho que las posibles valoraciones del injusto y sus diversas manifestaciones se encuentran ya recogidas (con completitud) en la formulación de los tipos penales y la aplicación de las reglas generales que los afectan. En su opinión, que compartimos, resulta que los tipos penales, y las reglas complementarias, sólo expresan rangos en los cuales la sentencia puede ser expresada, pero la concretización definitiva está entregada al juez. De este modo, se aprecia como los criterios del artículo 24 LRPA se refieren en muchos casos a cuestiones propias de la valoración de la conducta penal que ya han sido considerados, pero cuyo análisis puede ser refinado una vez que la subsunción de la conducta a un tipo legal ya se ha efectuado. Por ello, no es relevante que se considere en más de una ocasión una misma categoría de relevancia para el injusto, sino que sea valorado un mismo hecho o circunstancia más de una vez, lo que de acuerdo con esta lectura de la norma, no ocurre. De ahí, concluye la importancia del deber de fundamentación de la sentencia en su parte considerativa, en especial la subsunción de los hechos probados bajo los supuestos legales correspondientes, lo cual se vincula directamente con el deber de expresión de los criterios considerados para determinación de la pena. ${ }^{65}$

En cuanto al alcance general de los criterios, no obstante el tenor literal del encabezado del artículo 24, existe consenso en el sentido que su aplicación sirve tanto para la elección de la medida dentro del respectivo tramo, como para la determinación de su cuantía exacta cuando se trata de penas divisibles.

Hechas estas dos precisiones, pasamos a precisar el sentido y alcance que corresponde a cada uno de los criterios que establece el artículo 24 de la LRPA.

\subsection{La gravedad del ilícito:}

Un primer problema que puede generar la exegesis de este criterio, se refiere al sentido que corresponde atribuir a la poco feliz expresión "ilícito" en el contexto de la norma. Esto es, si la misma ha sido utilizada en un sentido restringido como sinónimo de "antijuridicidad penal", o si ha sido empleada como sinónimo de "delito". Por cierto, la adopción de una u otra postura incide directamente en su extensión, pues en el primer caso sólo podrían ser incluidas en él aquellas cuestiones vinculadas con la intensidad del injusto, en tanto que si se adopta la segunda solución, podrían envolverse también aspectos relacionados con el grado de culpabilidad del hechor. La historia fidedigna del establecimiento de la LRPA, parece dar cuenta de que la segunda constituye la interpretación correcta, pues según se lee en uno de los pasajes del Mensaje del Ejecutivo: "La Ley, además de estos límites,

\footnotetext{
${ }^{64}$ HORVITZ LENNON, “Determinación de las sanciones”, cit. nota no 55, pp. 103 y 113.

${ }^{65}$ MEDINA SCHULZ, "Sobre la determinación de pena", cit. nota no 3, pp. 216 y 217.
} 
establece como criterios que el Juez considerará para determinar la sanción a imponer su duración y cuantía, el número de infracciones, la gravedad de ellas y la edad del imputado, así como la concurrencia de circunstancias modificatorias de la responsabilidad penal (la cursiva es nuestra) ${ }^{66}$. En nuestra doctrina es de esta opinión Berrios. ${ }^{67}$ Aunque sin manifestarse explícitamente sobre el sentido de la expresión "ilícito", parece entenderla en el sentido de antijuricidad penal, Medina, quien al pronunciarse sobre su contenido, refiere aspectos vinculados sólo con el "disvalor de injusto", prescindiendo de la culpabilidad. ${ }^{68}$

A nuestro juicio, este criterio incluye únicamente las cuestiones relacionadas con la magnitud del injusto, pues los aspectos relacionados con la culpabilidad deben ser abordados a propósito del criterio establecido en la letra d) del artículo 24, esto es, la edad del adolescente infractor.

Por cierto, la precisión del contenido de este criterio dependerá del concepto de injusto del cual se parta. Como es sabido, el punto de vista clásico parte de un concepto de injusto vinculado a la lesión o puesta en peligro de un bien jurídico, en el que se integran luego los elementos subjetivos. Otro punto de vista considera, en cambio, que la esencia del injusto penal radica en la puesta en cuestión o el no reconocimiento o la desatención del Derecho, entendido no sólo como orden abstracto, sino comprendiendo también la relación jurídica con la víctima o la generalidad. ${ }^{69}$

Partiendo de un concepto clásico de injusto, son varios los factores que a la luz de este criterio se pueden considerar por el sentenciador y que pueden formar parte de la fundamentación de su sentencia.

Desde la perspectiva del injusto objetivo puede incidir en un mayor o menor desvalor el modo de ejecución del hecho. Así por ejemplo, pueden ser valorados para seleccionar una pena más grave la actuación especialmente violenta del autor de un robo con violencia, el ingreso en un lugar habitado, destinado a la habitación o sus dependencias encontrándose presente los moradores, o la comisión de una violación llevada a cabo sin precauciones para prevenir el embarazo de la víctima. En cambio, por regla general, el favorecimiento de la comisión del hecho por parte del ofendido da lugar a una disminución del injusto, por

\footnotetext{
${ }^{66}$ Sin embargo, se debe precisar que esta aseveración respecto a la gravedad del delito, fue hecha en el mensaje respecto del sistema contenido en el proyecto enviado por el ejecutivo al gobierno, el cual se caracterizaba por contemplar un catálogo de delitos considerados "infracciones graves" que eran los únicos que podías sancionarse con penas privativas de la libertad. Este régimen fue modificado durante la tramitación 'parlamentaria en el Senado, optándose por el sistema que en definitiva fue establecido en la Ley $\mathrm{N}^{\circ}$ 20.084. Respecto de los problemas que generó este cambio ver: CILLERO BRUÑOL, Miguel: "Ley $\mathrm{N}^{\circ}$ 20.084 sobre Responsabilidad Penal de Adolescentes", Anuario de Derechos Humanos, No 2 (2006), pp. 192 a 194.

${ }^{67}$ BERRÍOS DÍAZ, "El nuevo sistema", cit. nota nº 50, p. 168.

${ }^{68}$ MEDINA SCHULZ, "Sobre la determinación de pena", cit. nota $n^{\circ} 3$, p. 220.

${ }^{69} \mathrm{Al}$ analizar la incidencia del injusto en la formulación de un sistema dogmático de la individualización de la pena, se refiere a esta distinción, SILVA SÁNCHEZ, Jesús María, "La teoría de la determinación de la pena como sistema (dogmático): un primer esbozo", In Dret, № 2 (2007), [citado 2012-03-03], pp. 10 y 11., pp. 401-407. Disponible en: http://www.indret.com/pdf/426_es.pdf
} 
NÚÑEZ, Raúl y VERA, Jaime, "Determinación judicial de la pena,

Motivación y su control en el Derecho penal de adolescentes chileno".

exposición al riesgo, que puede incidir en la elección de una pena menos gravosa. ${ }^{70}$ Tratándose de delitos que contengan la infracción de un deber, también resulta posible cuantificar la intensidad de la infracción en vistas de precisar la gravedad de la infracción. Así por ejemplo, en los delitos de comisión por omisión, se puede cuantificar la gravedad de la infracción del deber de garante.

Tratándose del injusto subjetivo, cabe apreciar diferencias desde el punto de vista de la forma que adopte el título de imputación subjetiva (dolo o culpa). Respecto del dolo, considerando especialmente que la legislación común no suele contener diferencias penológicas a partir de las diferentes clases de dolo que propone la dogmática (directo, indirecto y eventual), este factor puede ser utilizado en la selección de la sanción dentro de los marcos del artículo 23 de la LRPA. En relación con la culpa, dado que la infracción de la norma de cuidado, también admite graduaciones cuantitativas y cualitativas, este también puede ser un factor apreciable desde la perspectiva de este criterio. También cabe apreciar en este momento la incidencia que puedan tener las motivaciones que impulsen el actuar del adolescente, así por ejemplo, motivaciones egoístas pueden incidir en una mayor pena, mientras que las motivaciones altruistas en una menor.

Otra forma de sistematizar el criterio de la gravedad del ilícito, puede valerse de las ideas afirmadas por Silva, quien propone distinguir entre injusto objetivo e injusto subjetivo. En este contexto, a partir del injusto objetivo, se puede establecer una diferenciación primero en el momento ex ante, desde el punto de vista cualitativo ponderando el nivel de riesgo creado y desde el punto de vista cualitativo, estableciendo el grado de probabilidad de lesión para el bien jurídico afectado. En el momento ex post, resulta también posible determinar el nivel de afectación real ocasionada al bien jurídico. Finalmente, desde el punto de vista del injusto subjetivo, cabe aún distinguir entre niveles de intención y grados de conocimiento. ${ }^{71}$ Aplicando estas ideas respecto de la operatividad del criterio previsto en el artículo 24 letra a) de la LRPA, resulta, por ejemplo, que si desde la perspectiva ex ante, mientras mayor riesgo creado exista cuantitativa y cualitativamente, desde la perspectiva $e x$ post, mayor sea afectación del bien jurídico y mientras mayores sean los grados de conocimiento e intención atribuibles al adolescente infractor, mayores razones existirán para fundamentar la imposición de una pena más severa de las previstas en los respectivos tramos del artículo 23 de la LRPA y viceversa, para la imposición de aquellas menos rigurosas.

\subsection{La calidad en que el adolescente participó en el hecho y el grado de ejecución de la infracción:}

Un importante sector de la doctrina, manifiesta que este criterio no cumple un rol preponderante en el proceso que conduce a la determinación de la sanción del adolescente. La razón que se esgrime es que este factor ya ha sido considerado en la etapa previa, en

\footnotetext{
${ }^{70}$ Se refiere a estos ejemplos similares a los propuestos, JESCHECK, Hans - Heinrich, Tratado de derecho penal. Parte general, Granada: Comares, 2002, p. 956, aunque lo hace con motivo del sentido y alcance del § 46 II 2 del Código Penal alemán, el cual establece como primer criterio de individualización de la pena el contenido de injusto y la culpabilidad del hecho.

${ }^{71}$ SILVA SÁNCHEZ, "La teoría de la determinación de la pena", cit. nota no 69, pp. 11 a 13.
} 
Polít. crim. Vol. 7, № 13 (Julio 2012), Art. 5, pp. 168 - 208.

[http://www.politicacriminal.cl/Vol_07/n_13/Vol7N13A5.pdf]

virtud de la remisión prevista en el artículo 21 de la LRPA, que obliga a apreciar, entre otras cuestiones, los aspectos sobre autoría, participación e iter criminis, por lo que una nueva valoración del mismo en esta fase, en detrimento del adolescente, vulneraría el principio non bis in idem. ${ }^{72}$

Sin embargo, en nuestra opinión, existen varias hipótesis que de acuerdo con una mayor depuración de los dos baremos establecidos, pueden generar razones a tener en cuenta por el juzgador al momento de adoptar su decisión respecto de la sanción a imponer.

En efecto, tratándose de cuestiones vinculadas con la autoría y participación, resulta que el modelo adoptado por nuestro Código Penal en el artículo 15, el cual equipara a la calidad de autoría supuestos que la doctrina considera de participación, posibilita establecer matices en la responsabilidad de varios adolescentes en un mismo hecho, los que inciden en la sanción seleccionable. De este modo, el adolescente que actúa ostentando un dominio directo o funcional del hecho, no puede ser sancionado con la misma pena que aquel que actúa en calidad de cooperador necesario. Lo mismo cabe predicar respecto del supuesto en que el delito se cometa con intervención de un instigador, quien también carece del dominio del hecho. En estos casos, la circunstancia de ostentar o no el dominio sobre el hecho, no ha sido considerada por el legislador en las etapas previas, pues conforme con las reglas generales todos merecen la calificación de autores, en consecuencia no hay afectación al principio non bis in idem posible. Un ejemplo, de lo planteado podría ser el caso de la comisión de un delito de robo con fuerza en las cosas, en que actúa un adolescente quien se limita a la realización de labores de vigilancia en las inmediaciones del lugar, mientras los demás intervienen mediante actos ejecutivos, ya sea el ejercicio de fuerza o la sustracción de especies. El primero, de acuerdo con la interpretación jurisprudencial dominante del artículo 15 del Código Penal, merecería la calificación de coautor del artículo numeral tercero, pero resulta que su distinta intervención en el hecho, puede ser apreciada en este caso para seleccionar una sanción de menor gravedad que la de sus coautores.

En cuanto a factores apreciables en la fundamentación, vinculados con el iter criminis, resulta que una situación similar a la expuesta, se produce en aquellos casos en que el legislador ha equiparado la pena de la tentativa, la frustración con la del delito consumado (artículos 450 inciso 1 del Código Penal y 17 de la Ley 20.000 de Drogas). En tales casos, a pesar que el legislador castiga los distintos grados de desarrollo del hecho con la misma pena, la circunstancia que las formas de ejecución imperfectas impliquen un grado de afectación menor para el bien jurídico (puesta en peligro) que la consumación (lesión), puede ser tenido en cuenta por el sentenciador para aplicar menos severas a las formas imperfectas. $^{73}$

\footnotetext{
${ }^{72}$ En este sentido, BUSTOS RAMÍREZ, Juan, Derecho penal del niño-adolescente (estudio de la Ley de Responsabilidad Penal del Adolescente), Santiago: Ediciones Jurídicas de Santiago, 2007, p. 66.

${ }^{73}$ Sin perjuicio de lo expresado, es posible también plantear la exclusión de estas normas, a pesar de que la remisión del artículo 21 de la LRPA incluye el artículo 55, que se refiere a estas hipótesis de tratamiento especial de hipótesis de autoría, participación e iter criminis. Tales estatutos constituyen una infracción al principio de proporcionalidad de las penas, que si bien no cuenta con consagración constitucional ni legal expresa en nuestro derecho, a propósito del derecho de adolescentes, como vimos, si cuenta con reconocimiento explícito en la Convención sobre los Derechos del Niño (artículo 40.4), tratado que debe ser
} 
NÚÑEZ, Raúl y VERA, Jaime, "Determinación judicial de la pena,

Motivación y su control en el Derecho penal de adolescentes chileno".

Por su parte, tratándose de delitos cuyo iter criminis, desde su inicio y hasta la consumación admite una fragmentación en varios hechos, resulta que cada uno de ellos puede vislumbrarse como una forma más perfecta de afectación del bien jurídico y servir en como criterio de selección de penas en función de su gravedad, es decir, mientras más cercana se encuentre la conducta de la consumación, más grave es la valoración que debe efectuarse respecto de la misma para efectos de la selección de la pena y viceversa.

\subsection{Las atenuantes 0 agravantes de responsabilidad:}

En materia de agravantes, hay quienes postulan que las mismas no pueden ser utilizadas en esta fase para seleccionar sanciones más severas, pues lo anterior infringiría el principio non bis in idem. ${ }^{74}$ Concordamos con Medina, que lo esto es matizable, aunque tal autor concluye que tales matices se deducen del hecho que los supuestos fácticos sustentadores de la concurrencia de las circunstancias modificatorias son graduables, ${ }^{75}$ mientras nosotros opinamos que esta es una cuestión estrechamente relacionada con la fundamentación de las circunstancias modificatorias, tema que abordaremos como cuestión previa.

A propósito del fundamento de las circunstancias modificatorias, resulta posible abstraer de ellas algunos criterios uniformes, reconducibles a su vez en un entendimiento y fundamentación común de todas ellas. Tales criterios toman como punto de partida los lineamentos generales de la teoría del delito y en virtud de ello, han sido entendidos de la más diversa forma. Así, según Mir Puig, el fundamento común de las circunstancias modificatorias viene dado porque involucran una disminución en el contenido de injusto, el grado de imputación personal o la conveniencia de pena. ${ }^{76}$ En esta misma línea Rivacoba, entiende que el fundamento de las circunstancias modificatorias, se encuentra, además de en cuestiones asociadas al mayor injusto o culpabilidad del hecho, en las valoraciones dominantes que en la sociedad, hacen objeto de una reprobación más o menos intensa respecto del hecho. ${ }^{77}$ Estas razones que han sido tomadas en cuenta por el legislador en la fundamentación de las circunstancias, pueden concurrir con una mayor o menor intensidad en cada caso.

Así por ejemplo, tratándose de agravantes cuya fundamentación se relaciona con un mayor injusto penal, como podría ser el caso de la alevosía, mientras más intenso sea el estado de indefensión en que se encontraba la víctima (de rodillas, de espaldas, dormido, etc.), mayores razones existirán para imponer una pena más severa dentro del respectivo tramo del artículo 23. En el caso de la reincidencia, cuyo efecto agravatorio puede vincularse con consideraciones político criminales que exigen aplicar una mayor pena a quien manifiesta un comportamiento contumaz con el ordenamiento jurídico, resulta que no es lo mismo que esta circunstancia se configure por tener una única condena anterior, a que se trate de un

considerado en el proceso que conduce a la imposición de la condena por imperativo del artículo 1, inciso 2 de la LRPA.

${ }^{74}$ En este sentido, BUSTOS RAMÍREZ, Derecho penal del niño-adolescente, cit. nota no 72, p. 67.

${ }^{75}$ MEDINA SCHULZ, "Sobre la determinación de pena", cit. nota $\mathrm{n}^{\circ}$ 3, p. 221.

${ }^{76}$ MIR PUIG, Santiago, Derecho Penal Parte General, $7^{\mathrm{a}}$ edición, Barcelona: Editorial Reppertor, 2005, pp. 603 y 604.

${ }^{77}$ RIVACOBA Y RIVACOBA, Manuel, "Las circunstancias modificativas de la responsabilidad criminal en la teoría general del delito", Revista doctrina penal, año 11, № 43 (1988), p. 476. 
Polít. crim. Vol. 7, № 13 (Julio 2012), Art. 5, pp. 168 - 208.

[http://www.politicacriminal.cl/Vol_07/n_13/Vol7N13A5.pdf]

sujeto multireincidente. Nótese como en ambos casos, este criterio del artículo 23, permite matizar el tratamiento para las diversas hipótesis que pueden surgir.

En materia de atenuantes, se produce una situación idéntica, que repercute en beneficio del adolescente, para la imposición de una pena menos severa, cuando las razones que posibilitan la rebaja del castigo concurran en intensidades graduables. Este podría ser el caso la atenuante de colaboración substancial en el esclarecimiento de los hechos, la cual a nuestro juicio se fundamenta en consideraciones político-criminales que determinan un menor castigo cuando existe una conducta contributiva del imputado con la acción de la justicia. Puede suceder que existiendo colaboración, esta incida en aspectos muy determinantes de esclarecimiento del hecho y la participación del imputado por parte del órgano persecutor, razón que pueden ser consideradas por el juez a la hora de seleccionar una sanción menos severa dentro de los ramos respectivos.

\subsection{La edad del adolescente infractor:}

Considerando la posición que hemos adoptado respecto del alcance del criterio previsto en la letra a) del artículo 24 de la LRPA, circunscrito exclusivamente a los aspectos relacionados con el injusto, es a propósito de este criterio que el juez debe apreciar las cuestiones vinculadas con la culpabilidad del hechor (imputación personal). ${ }^{78}$ En particular, tiene aquí importancia si la motivabilidad del menor o la exigibilidad de un comportamiento adecuado a la norma se encontraban limitadas en relación con el desarrollo acorde a su edad. En otras palabras, en este punto interfieren todos aquellos factores que condicionan las posibilidades del adolescente de motivarse a actuar conforme con los mandatos que impone la norma penal primaria.

Nuestra doctrina, tiende a incluir en este criterio, las eventuales diferencias de trato que aparecen plasmadas en la ley, respecto de los dos tramos de edad que se contemplan (14 a 16 años y 16 a 18 años). De este modo, en el proceso de selección de la sanción, corresponde siempre asignar un tratamiento menos severo al adolescente situado en el primer tramo, en detrimento de quienes se encuentran en una edad más cercana a la adultez. $^{79} \mathrm{Si}$ bien es cierto, esta aseveración parece correcta como punto de partida, creemos que constituye una visión más bien limitada del criterio.

Un primer aspecto que parece necesario despejar en el intento por precisar el alcance de este criterio, exige determinar cuál concepto de edad tiene que considerar el sentenciador, esto es, la edad cronológica o, por llamarla de alguna manera, la edad mental del adolescente. La primera opción presenta la ventaja que conduce a soluciones uniformes en la gran mayoría de los casos. Sin embargo, siempre existen casos límites, en los cuales no existe plena coincidencia entre el dato cronológico y el desarrollo cognitivo esperable y la madurez del adolescente que es juzgado, circunstancias que pueden ser acreditadas mediante el recurso a pruebas periciales psiquiátricas y psicológicas. Si bien es cierto, estas situaciones cuando revisten cierta intensidad pueden dar lugar a la apreciación de causales

\footnotetext{
${ }^{78}$ Lo anterior, en el entendido que el criterio desempeña un rol atenuador y no incrementador de la pena. En este mismo sentido, SILVA SÁNCHEZ, "La teoría de la determinación de la pena", cit. nota nº 69, p. 9.

${ }^{79}$ MEDINA SCHULZ, Gonzalo, "Sobre la determinación de pena", cit. nota nº 3, p. 222.
} 
NÚÑEZ, Raúl y VERA, Jaime, "Determinación judicial de la pena, Motivación y su control en el Derecho penal de adolescentes chileno".

de inimputabilidad o a una eximente incompleta, a nuestro juicio pueden ser también consideradas por el juez para decidir acerca de la naturaleza de la pena a imponer, sin que ello afecte el principio non bis in ídem. Incluso, en aquellos casos en que estas circunstancias por su menor intensidad, no determinen la configuración de eximentes completas o incompletas, podrían ser apreciadas bajo el prisma de este criterio y repercutir en la selección de una pena menos intensa.

Otro aspecto que puede ser abordado a la luz de este criterio, se refiere al llamado "error de comprensión", 80 entendido como imposibilidad o seria dificultad para comprender la antijuridicidad material del hecho. Tratándose de los adolescentes, estos en comparación con los adultos, debido a su menor experiencia y su gran distancia respecto del sentido de ciertas instituciones sociales, se les hace muy difícil comprender el significado antijurídico de ciertas prohibiciones penales, especialmente aquellas que atentan en contra de bienes jurídicos colectivos. Así, aun cuando los adolescentes sepan que ciertas falsificaciones, delitos informáticos, o incluso actos de consumo y microtráfico de drogas están prohibidos, seguramente les parecerán simples expresiones arbitrarias del universo normativo adulto, respecto de conductas que "no dañan a nadie". Para los adolescentes, entonces, la motivabilidad por estas normas es menor, justamente por la dificultad o, en ciertos casos, prácticamente la imposibilidad de comprender la antijuridicidad material del hecho. Frente a la disyuntiva de tratar esta clase de error como un auténtico error de prohibición, siempre queda el recurso ha abordarlo como una cuestión que en función de la edad, incide en una menor culpabilidad y termina repercutiendo en la selección de una pena de menor magnitud.

Finalmente, por incidir en cuestiones relativas a la culpabilidad, puede resolverse mediante la aplicación de este criterio la situación de aquellos adolescentes con serias desventajas socioeconómicas, las cuales incidan en su comportamiento, interfiriendo en sus posibilidades de motivarse a actuar con arreglo a la norma Un ejemplo de esta situación, podría ser el caso de un adolescente con un retraso escolar de varios años y que vive en situación de marginalidad socioeconómica, respecto de la comisión de delitos no violentos en contra de la propiedad, a quien no puede exigirse el mismo grado de motivación respecto de uno que ha recibido un mejor estándar de educación y cuenta con recursos y posibilidades para procurar sus necesidades sin cometer este tipo de delitos.

\subsection{Extensión del mal causado por el delito:}

La inclusión de este criterio, junto con el relativo a la concurrencia de circunstancias atenuantes y agravantes, constituye una réplica de lo establecido en el artículo 69 del Código Penal respecto del régimen de determinación de la pena de adultos. De ahí que para la definición de su sentido y alcance, podemos valernos de las consideraciones doctrinales sostenidas a propósito de la norma mencionada.

Según van Weezel, esta cláusula comprendería los siguientes extremos: i) los resultados típicos no asociados por sí solos en el tipo a incrementos vinculantes de penalidad (Por

\footnotetext{
${ }^{80}$ Sobre esta noción, ver: HERNÁNDEZ BASUALTO, "El nuevo Derecho penal de adolescentes", cit. nota $\mathrm{n}^{\mathrm{o}} 6, \mathrm{p} .213$.
} 
ejemplo: el grado de deformidad -siempre dentro de lo "notable"- causado por las lesiones del Art. $397 \mathrm{~N}^{\circ}$ 1); ii) las repercusiones, que necesariamente serán extratípicas, derivadas de la tentativa y del delito frustrado; iii) las demás repercusiones extratípicas del hecho, tanto en los delitos de resultado como en los de mera acción (Por ejemplo: la magnitud del perjuicio económico que sufre el tenedor de un cheque sin fondos, en el delito del Art. 22 del DFL 707 sobre Cuentas Corrientes Bancarias y Cheques). ${ }^{81}$ Así las cosas, queda disipada la duda respecto de que la voz resultado en la redacción de la norma, tiene un alcance más extenso que el sentido usualmente atribuido a propósito de los delitos de resultado material, esto es, como transformación del mundo externo imputable objetivamente a la conducta delictiva.

No obstante lo expresado, una aplicación rigurosa de los principios de legalidad y culpabilidad, cuya vigencia debe ser maximizada tratándose del juzgamiento de adolescentes, supone una depuración de las consecuencias típicas y extratípicas que pueden ser introducidas mediante la aplicación de este criterio en términos desfavorables para el adolescente. De este modo, desde el punto de vista de la imputación objetiva, sólo cabría incluir aquellas que queden inmersas en el fin de protección de la norma penal infringida y desde la perspectiva subjetiva, las que hayan sido a lo menos previsibles para el autor.

Varios de los supuestos propuestos por van Weezel, pueden ser analizados a la luz del criterio de la gravedad del ilícito de la letra a) del artículo 24 de la LRPA e incidir en la elección de la pena. Sin embargo, es posible encontrar algunos ejemplos distintos, que, además, satisfacen la doble exigencia que planteábamos. Tal sería el caso de las secuelas de índole psicológica que se producen en la víctima de un delito sexual, especialmente cuando su comisión va acompañada del empleo de medios violentos o se trata de víctimas menores. Otros ejemplos, pueden ser la muerte del drogadicto, frente a la comisión de un delito de tráfico, más aún si la conducta recae sobre sustancias de conocida toxicidad o una alta gradación alcohólica, muy por sobre el rango de un gramo de alcohol por litro de sangre, que determina la configuración del delito de manejo en estado de ebriedad, circunstancia que si bien no es considerada en el tipo para agravar la pena, si repercute en una mayor afectación del bien jurídico seguridad para el tráfico viario. ${ }^{82}$

En cuanto a los factores que pueden incidir en la elección de una pena menos rigurosa, por cierto no corresponde establecer la limitación objetiva-subjetiva que se propuso, pues no existe en este caso afectación posible a los principios de legalidad y culpabilidad. Tal sería el caso, en que no se verifique íntegramente la situación que determina la pluriofensividad de ciertos delitos, especialmente de contenido patrimonial, como por ejemplo, el empleo de un arma de fantasía en la perpetración de un delito de robo con intimidación, o el supuesto en que el autor adolescente que incurre en un delito de robo en lugar habitado, supongamos

\footnotetext{
${ }^{81}$ VAN WEEZEL, Alex, "Determinación de la Pena Exacta: El Artículo 69 del Código Penal", Ius et Praxis [online], vol.7, $\mathrm{N}^{\circ} 2$ (2001) [citado 2012-03-08], pp. 401-407. Disponible en: $\leq$ http://www.scielo.cl/scielo.php?script=sci arttext\&pid=S0718-00122001000200017\&lng=es\&nrm=iso $>$. ISSN 0718-0012. doi: 10.4067/S0718-00122001000200017.

${ }^{82}$ Bajo esta misma premisa, Bustos propone otro ejemplo: el desvalijamiento de un lugar no habitado, en que para entrar el adolescente destroza totalmente una muralla. Cfr. BUSTOS RAMÍREZ, Derecho penal del niño-adolescente, cit. nota $\mathrm{n}^{0} 72$, p. 67.
} 
NÚÑEZ, Raúl y VERA, Jaime, "Determinación judicial de la pena,

Motivación y su control en el Derecho penal de adolescentes chileno".

un joven de 14 años recién cumplidos, presenta una complexión física manifiestamente inferior a la de la víctima adulta. En ambos casos, la extensión del mal que se produce respecto de la seguridad e integridad de la víctima se ve minimizada, factor que podría ser utilizado por el tribunal para la elección de una pena de las de menor gravedad del tramo de que se trate.

\subsection{La idoneidad de la sanción para fortalecer el respeto del adolescente por los derechos y libertades de las personas y sus necesidades de desarrollo e integración social:}

La inclusión de este criterio, como una especie de cláusula de cierre del proceso de individualización de la sanción, no es una mera coincidencia. Muy por el contrario, de esta forma son conjugados todos factores que deben incidir en la elección de la pena y ser incorporados en la fundamentación de la misma. Hasta ahora, todos los criterios analizados encuentran algún nexo con el sistema de imputación, ya sea a nivel de injusto o a nivel de culpabilidad. La particularidad de este criterio, radica en que a través de él se incorpora un elemento teologal al sistema, es decir, la orientación del proceso hacia los fines de la pena. Esto involucra reconocer, como acertadamente ha anotado Silva, que el juez, especialmente al momento de individualizar la pena, está ejecutando un acto de política criminal. ${ }^{83}$

Respecto del sentido mismo de la idea de idoneidad establecida a propósito de este criterio, resulta plenamente sostenible lo aseverado por Cillero, en cuanto a que debe ser entendida como la aptitud de la sanción para cumplir los fines preventivos de la ley en el caso concreto ${ }^{84}$ En este mismo orden de ideas, la idoneidad se encontraría en íntima conexión con el principio de proporcionalidad en sentido amplio, el cual se integraría por las nociones de necesidad, idoneidad y proporcionalidad en sentido estricto. ${ }^{85}$

Específicamente, los fines que debe considerar el juez conforme con el criterio de idoneidad, son expresados en el artículo 20 de la ley: hacer efectiva la responsabilidad de los adolescentes por los hechos delictivos que cometan, de tal manera que la sanción forme parte de una intervención socioeducativa amplia y orientada a la plena integración social. En consecuencia se trata de una finalidad doble y que opera en distintos ámbitos.

La primera finalidad que se conecta con este criterio, esto es, hacer efectiva la responsabilidad del adolescente supone una aplicación diferenciada del sistema de imputación (objetiva, subjetiva y personal) del derecho penal al adolescente infractor, por las limitaciones que impone la idea de interés superior del menor plasmada en el artículo 2. Es decir, se trata una aplicación del sistema de imputación, pero con una maximización de

\footnotetext{
${ }^{83}$ Aunque reconociendo que no se trata de un acto de política criminal directa, pues la consideración directa de los fines de la pena envuelve el riesgo que las decisiones sean el producto del intuicionismo, puro decisionismo o, sin más, la arbitrariedad, del juzgador. Por lo anterior, es preciso que esa política criminal se canalice por vías dogmáticas. En el caso de nuestro sistema de individualización de la pena de adolescentes, esta canalización se consigue, entre otras cosas, mediante la fijación del sentido preciso del criterio de la idoneidad. Cfr. SILVA SÁNCHEZ, "La teoría de la determinación de la pena”, cit. nota no 69, pp. 4 y 5.

84 CILlERO BRUÑOL, Miguel, Consideraciones para la aplicación del criterio de idoneidad en la determinación de las sanciones en el Derecho Penal de adolescentes chileno, Documento de Trabajo $\mathrm{N}^{\circ} 13$, Unidad de Defensa Penal Juvenil, Defensoría Penal Pública, año 2008, p. 17.

${ }^{85}$ MEDINA SCHULZ, "Sobre la determinación de pena", cit. nota n 3, p. 225.
} 
las garantías que lo limitan (legalidad, ${ }^{86}$ intervención mínima, lesividad, culpabilidad y proporcionalidad). El entendimiento de esta finalidad en clave garantista, impide que por la vía de la misma, se pretendan introducir en esta fase consideraciones de corte retributivo y preventivo general negativo características del sistema de adultos, que en la mayoría de las ocasiones conducen a la imposición de la pena sobre la base de un acto de decisionismo arbitrario, carente de racionalidad. A nuestro juicio cualquier fundamentación de la sentencia, que a la hora de seleccionar la sanción, sobre la base del criterio de la idoneidad, pretenda introducir consideraciones en el sentido expuesto, debe ser rechazado de plano.

El segundo objetivo vinculado con la idoneidad, consistente en promover que la sanción forme parte de una intervención socioeducativa amplia y orientada a la plena integración social, vincula al proceso de individualización de la pena con el ideario preventivo especial o resocializador, que constituye el principal paradigma que inspira al sistema. Este fin, sin embargo, no puede justificar por si sólo la intervención punitiva estatal, sino que más bien está llamado a cumplir un rol limitador de la misma. Sobre la base de estas premisas, resulta que el ideario preventivo especial, debe operar sobre la base de dos limitantes: i) el rechazo de toda forma de resocialización que prescinda de la voluntad del penado y que pretenda de interferir en su sistema de valores; ii) procurar evitar al máximo los efectos desocializadores de las penas, especialmente de aquellas que sean privativas de la libertad. 8788 Esta formulación sobre el contenido del fin resocializador, impide que la intervención punitiva estatal se conciba a la usanza del antiguo sistema tutelar, esto es, como destinada a otorgar una protección o tutela del adolescente, en el entendido que por la vía de la pura imposición de una condena se pueden conseguir efectos favorables para el penado. De acuerdo con lo expresado, se debe prescindir en la sentencia de cualquier línea argumentativa que, a partir del criterio de la idoneidad de la sanción, pretenda fundar su elección e imposición en un supuesto efecto benéfico para las posibilidades de reinserción futura del adolescente. ${ }^{89}$

\footnotetext{
${ }^{86}$ Este principio constituye una de las garantías fundamentales en la construcción del moderno derecho penal de adolescentes y al igual que en el derecho penal de adultos, se manifiesta en cuatro garantías: criminal, penal, judicial y de ejecución. Cfr. AYO FERNÁNDEZ, Manuel, Las garantías del menor infractor, Navarra: Aranzadi, 2004, p. 164.

87 Sobre el concepto de prevención especial, su evolución crítica y reformulación, ver: BESIO HERNÁNDEZ, Martín, Los criterios legales y judiciales de individualización de la pena, Valencia: Tirant lo Blanch, 2011, pp. 77 a 83.

${ }^{88}$ En un sentido parcialmente diferente al propuesto, Couso manifiesta que estos fines socioeducativos a los que aspiran las medidas contempladas en la ley, deben entenderse en el sentido de efecto de la pena, como efecto intimidatorio individual y, además, resocializador. Es decir, parafraseando al mismo autor, en el ámbito del derecho penal juvenil los fines educativos o socioeducativos significan, fundamentalmente, prevención especial, tanto, desde una perspectiva positiva resocialización y negativa intimidación. Cfr. COUSO SALAS, Jaime, "Principio educativo y (re)socialización en el Derecho penal juvenil", Justicia y Derechos del Niño, No 8, UNICEF, Santiago (2006), pp. 51 y 52.

${ }^{89}$ Este recurso argumentativo, era muy común durante la vigencia del sistema tutelar y derivó en una severa crisis de eficacia, originada por la circunstancia que no fueron pocos los casos en que medidas de protección, se imponían sin la menor necesidad ni justificación, aunque fundamentadas bajo la falacia de su carácter "pedagógico", "tutelar" y "protector". En este sentido, DO AMARAL E SILVA, Antonio Fernando, "La protección como pretexto para el control social arbitrario de los adolescentes o la supervivencia de la doctrina de la situación irregular" en: GARCÍA MENDEZ, Emilio (Comp.), Adolescentes y responsabilidad penal, Buenos Aires: Ad Hoc, 2001, p. 122.
} 
NÚÑEZ, Raúl y VERA, Jaime, "Determinación judicial de la pena, Motivación y su control en el Derecho penal de adolescentes chileno".

El principal inconveniente que puede presentar la operatividad del criterio de la idoneidad de la sanción, tiene lugar cuando entra en colisión con los demás factores que deben ser apreciados al momento de seleccionar. El supuesto límite se produce cuando la intensidad del injusto del hecho y los factores de imputación personal, sugieren la imposición de una pena grave, generalmente de aquellas privativas de libertad, mientras el criterio de idoneidad impone la necesidad de no recurrir a esa clase de penas. Un ejemplo, podría ser el caso de un adolescente que incurre en un comportamiento que merece la calificación de crimen, pero que presenta elementos favorables de socialización (desarrollo escolar acorde a su edad, calificación laboral, etc.) que hacen poco aconsejables la imposición de una pena de internación. A nuestro juicio, este conflicto entre los criterios, en virtud de una adecuada consideración a la idea del interés superior del menor, debe resolverse otorgando primacía al ideario preventivo especial positivo, por sobre las otras consideraciones de índole retributiva o preventivo general negativa, de modo que el juez debe seleccionar en este caso, la pena que resulte menos lesiva de las garantías del menor. ${ }^{90}$

De las consideraciones expuestas, es posible inferir que la forma como el legislador plasma la finalidad de las sanciones en la LRPA, conjuga aspectos de la teoría del neoproporcionalismo, ${ }^{11}$ es decir, la búsqueda en una primera fase, de una pena

\footnotetext{
${ }^{90}$ Esta es una situación que se ve agravada, cuando tratándose de crímenes, la aplicación de las reglas sobre determinación de la duración de la sanción, conducen a la aplicación del tramo número del artículo 23 de la LRPA, el cual sólo faculta al tribunal para imponer la pena de internación en régimen cerrado. Una posible solución, pasa por recurrir en este caso a la sanción mixta del artículo 19 inciso 1 de la LRPA. En este mismo sentido, CILLERO BRUÑOL, Consideraciones para la aplicación, cit. nota no 84, p. 11.

${ }^{91}$ Es posible diferenciar, en principio, tres corrientes o teorías que han tratado de brindar una respuesta al problema además del neoproporcionalismo.

La primera teoría es la de pena exacta o puntual (Punktstrafe). Los partidarios de esta teoría afirman que el juez debe determinar la pena conforme a aquella que resulta exactamente ajustada al caso. Es decir, para cada caso determinado sólo existe una determinada pena concreta, que sólo no puede ser conocida por los defectos cognitivos humanos. Si bien, hay autores que la vinculan con la determinación de la pena conforme a la culpabilidad, no es la opinión mayoritaria. En cuanto a las críticas, las mismas apuntan a dos ámbitos. El primero, al carácter irrealizable de la pretensión de diferenciar todo y cada uno de los posibles resultados y variaciones de los tipos penales, así como su traducción en valores numéricos. La segunda crítica apunta en al ámbito recursivo, el cual se trasforma en incontrolable e infinito al establecer como criterio de determinación con tal exactitud.

La teoría del espacio de juego o margen de libertad (Spielraumtheorie). Se trata de una teoría elaborada por la jurisprudencia alemana, y conforme a ella la pena ajustada a la culpabilidad comprende un marco determinado entre un máximo y un mínimo, y no es, como propone la teoría puntual, una magnitud exacta, sino que existe un margen de libertad que se limita, en grado mínimo, por la pena ya adecuada a la culpabilidad y, en grado máximo, por la pena todavía adecuada a la culpabilidad. Con todo, el problema es que no soluciona el problema del margen de discrecionalidad en la determinación de la pena, ya que sólo excluye casos evidentes de penas que superan la culpabilidad del sujeto, pero no entrega criterios para eliminar la discrecionalidad en la generalidad de los casos.

La tercera teoría se conoce indistintamente como la del valor posicional o del valor de empleo (Stellungswerttheorie). Esta postura presenta una solución de la antinomia de los fines de las penas, desconcertante por su facilidad, al pretender tener en cuenta, tanto el punto de vista de la retribución de la culpabilidad, como el de la prevención, pero atribuyendo a cada uno un valor de empleo en la ley completamente diferente. Representa una alternativa a la teoría del espacio de juego, que a través de una parcialización del proceso de determinación de pena, considera que la fijación del quantum de la sanción ha de atenerse exclusivamente a la culpabilidad por el hecho, siendo esto una cuestión necesariamente previa. Acto seguido, al momento de determinar la clase de sanción y su ejecución se deben atender a los fines preventivos.
} 
Polít. crim. Vol. 7, № 13 (Julio 2012), Art. 5, pp. 168 - 208.

[http://www.politicacriminal.cl/Vol_07/n_13/Vol7N13A5.pdf]

proporcionada al hecho (magnitud de injusto y grado de culpabilidad), con la teoría del valor relativo, al introducir en la segunda fase, consideraciones vinculadas con los fines de la pena, más propiamente consideraciones preventivo especiales positivas.

\section{El recurso de nulidad.}

Así las cosas, una vez revisados los criterios que inciden en la determinación judicial de la pena, cabe preguntase si los defectos en su aplicación o interpretación pueden constituir vicios de la sentencia, que con tal carácter, den lugar a una revisión de la misma a través del recurso de nulidad.

En el sistema procesal penal chileno, el recurso de nulidad representa el mecanismo por el cual se solicita al superior jerárquico de un tribunal que invalide el juicio oral o la sentencia, o solamente esta última, cuando en cualquier etapa del procedimiento o en el pronunciamiento de la sentencia se hubiere infringido sustancialmente derechos o garantías asegurados por la Constitución o por los tratados internacionales ratificados por Chile que se encuentren vigentes o cuando, en el pronunciamiento de la sentencia, se hubiere hecho una errónea aplicación del derecho que hubiere influido en los dispositivo del fallo. ${ }^{92}$

Con el establecimiento del recurso de nulidad penal, el legislador nacional buscó salvar el gran escollo dogmático que hubiera significado mantener un recurso de apelación incompatible con el nuevo diseño institucional de procedimientos orales y sujetos al sistema probatorio de libre apreciación de la prueba, como con la propia actividad desarrollada por el juez al resolver un caso, que como señalamos al comienzo no es otro que un discurso de aplicación o adecuación. Al mismo tiempo, el reemplazo del tradicional recurso de casación por el de nulidad permite, por una parte, liberarse de la tradición excesivamente formalista que siempre ha acompañado al instituto, como también por otra, escapar de la propia autocomprensión que nuestra Corte Suprema tiene de la Casación, que por decir lo menos, bordea lo racionalmente aceptable. ${ }^{93}$

En cuanto a las causales, es posible diferenciar dos grandes grupos de causales que posibilitan la interposición del recurso de nulidad. Efectivamente, se puede distinguir en primer término las causales genéricas o relativas, por cuanto su invocación deberá extraerse y configurarse dentro de los marcos normativos establecidos por el artículo 373 del Código

Sobre la teorías ver, entre otros: MAGARIÑOS, Mario, "Hacia un criterio para la determinación judicial de la pena", en: MAIER, Julio (Comp.), Determinación judicial de la pena, Buenos Aires: Editores del Puerto, 1993, pp. 74 y ss.; ZIFFER, Patricia, Lineamientos de la determinación de la pena, Buenos Aires: Ad-Hoc, 1996, pp. 49 y ss.; ROXIN, Claus, "Prevención y determinación de la pena", en: Fundamentos políticocriminales del Derecho penal, Buenos Aires: Hammurabi, 2008, pp. 169 y ss.; y, MEDINA SCHULZ, "Sobre la determinación de pena", cit. nota n 3 , pp. 204 y ss.

${ }_{92}$ Monográficamente sobre el tema en Chile consultar por todos: CORTEZ MATCOVICH, Gonzalo, El recurso de nulidad. Doctrina y jurisprudencia, Santiago: LexisNexis, 2006, passim y RIEUTORD ALVARADO, Andrés, El recurso de nulidad en el nuevo proceso penal, Santiago: Editorial Jurídica de Chile, 2007, passim.

${ }^{93}$ Para un análisis y crítica de la labor de la Corte Suprema como Tribunal de Casación civil ver: ATRIA LEMAITRE, Fernando, "La Casación como problema", Revista de Derecho, $\mathrm{N}^{\circ} 2$ (2006), Universidad Adolfo Ibáñez, Legis, Santiago, pp. 249 y ss. 
NÚÑEZ, Raúl y VERA, Jaime, "Determinación judicial de la pena, Motivación y su control en el Derecho penal de adolescentes chileno".

Procesal Penal. Es decir, el Legislador estableció dos causales genéricas de nulidad dentro de las cuales el recurrente deberá subsumir la actuación o resolución que estime nula, señalando al mismo tiempo la normativa que estimó vulnerada. En estos supuestos, se podrá solicitar la nulidad del juicio y de la sentencia o sólo esta última, dependiendo de dónde se verificó el vicio denunciado.

La segunda clase de causales son denominadas causales específicas o absolutas de nulidad, ya que ellas se encuentran taxativamente enumeradas en el artículo 374 del Código Procesal Penal. En esta hipótesis el legislador entrega un catálogo limitado de causales, las cuales importan una situación procesal determinada, que de comprobarse en la práctica, determinará siempre la nulidad del juicio y de la sentencia.

Así las cosas, el control vía recurso de nulidad de la determinación judicial de la sanción y en especial de los criterios del artículo 24 LRPA, se debería centrar en las causales genérica del 373 letra b) y la absoluta del 374 letra d) del Código Procesal Penal.

\subsection{La falta de fundamentación como causal.}

Como se señaló en otra parte de este trabajo, la garantía constitucional del deber de motivar las resoluciones judiciales alcanza a los criterios enumerados en el artículo 24 de LRPA. En efecto, incluso si el legislador no hubiere señalado en la disposición antes mencionada de manera explicita esta obligación, la misma se podría desprender de la garantía del debido proceso reconocida en el artículo $19 \mathrm{~N}^{\circ} 3$ de la Constitución Política de la República. ${ }^{94}$

La pregunta que de inmediato surge es: ¿Cuándo se entiende superado el estándar que fija la garantía constitucional del deber de motivar las resoluciones respecto de los criterios señalados por el legislador en el artículo 24 de LRPA? La lógica nos señala que la mera enunciación de los mismos en una sentencia no sería suficiente para entender superado el estándar. En efecto, la sola invocación formal de los criterios del artículo 24 de LRPA no permite dar superado el parámetro impuesto por nuestro sistema procesal penal.

El estándar que impone la garantía sólo se entenderá superado cuando la sentencia dé cuenta de qué criterios son los aplicables al caso concreto y, a continuación, pronunciándose sobre cada uno de ellos de acuerdo con los criterios de evaluación mencionados en el apartado número 5 del trabajo. Así es controlable, por el tribunal de nulidad, que el juez de instancia haya ignorado algún criterio alegado por los intervinientes y que no se haya expresado, fundadamente, sobre las alegaciones que sobre el punto se hayan realizado.

Una cuestión que no se puede olvidar es que nuestro juicio oral reconoce la división en dos períodos o fases, siguiendo en este punto el modelo angloamericano. En efecto, en este sistema se distinguen dos fases dentro del juicio oral, a saber: a) La primera fase se

\footnotetext{
${ }^{94}$ Con todo, se puede señalar de esta causal en nuestra doctrina ha originado un interesante debate, pero circunscrito al problema de la falta de valoración de la prueba. Ver entre otros trabajos: HORVITZ LENNON/LÓPEZ MASLÉ, Derecho procesal penal chileno, cit. nota ${ }^{\circ}$ 49, pp. 419 y ss.; y, RIEUTORD ALVARADO, El recurso de nulidad, cit. nota n ${ }^{\circ} 92$, pp. 66 y ss.
} 
Polít. crim. Vol. 7, № 13 (Julio 2012), Art. 5, pp. 168 - 208.

[http://www.politicacriminal.cl/Vol_07/n_13/Vol7N13A5.pdf]

pronuncia sobre la culpabilidad y en la cuál interviene el Jurado y b) La segunda fase sobre la pena sin intervención del Jurado (pues es competencia del juez letrado). Por otro lado, en el sistema continental de juicio oral la prueba sobre la comisión del hecho y sobre las circunstancias relevantes para la determinación de las consecuencias jurídicas se produce en un juicio oral unificado. ${ }^{95}$

Efectivamente, en los Estados Unidos de América del Norte la segunda fase de denomina Sentencing. En dicha fase se procede a la fijación de la pena concreta que sigue a la declaratoria de responsabilidad por parte del Jurado y que, por regla general, su determinación le corresponde al juez letrado. ${ }^{96}$

En este orden de ideas, el artículo 40 de LRPA señala que la audiencia de determinación de pena del artículo 343 del Código Procesal Penal se realizará de forma obligatoria en todos los casos de sentencias condenatorias. Así las cosas, queda claro que el momento de discusión sobre la aplicación de los criterios y reglas relevantes para la fijación de la sanción es la audiencia de determinación de pena. Es precisamente esta la oportunidad procesal para que los intervinientes esgriman los argumentos pertinentes a la individualización de la ley aplicable.

Para Medina, si el sistema procesal penal nacional reconoce una estructura adversarial con un órgano persecutor separado de la jurisdiccional y mecanismo de defensa obligatoria, el deber del juez en cuanto al pronunciamiento sobre los criterios de determinación de pena se debiese extender, a lo menos, a las alegaciones de las partes, indicando si estas son acogidas o no, y el porqué de ello, así como la forma en que son aplicables en caso de acogerse. ${ }^{97}$

Así las cosas, las argumentaciones jurídicas que conducen a determinada sanción son, en parte, el resultado de las reflexiones que proceden del análisis de la parte expositiva de la sentencia y por ello, no se diferencian de los razonamientos destinados a subsumir la conducta punible bajo normas penales concretas.

El problema es que la exigencia de fundamentación ha sido entendida desde una perspectiva formal, en cuanto sólo da pie para exigir de la sentencia que explicite las razones que llevan a tal o cual decisión. El inconveniente de si las razones utilizadas son o no correctas $^{98}$ sería una problema que no tendría solución en sede de la causal en cometo,

\footnotetext{
${ }^{95}$ Para una crítica del modelo continental ver: ROXIN, Claus, Derecho procesal penal, Buenos Aires: Editores del Puerto, 2000, pp. 378 a 380.

${ }^{96}$ PIZZI, William, "Sentencing in US: An Inquisitorial Soul in an Adversarial Body?", en: Crime, Procedure and Evidence in a Comparative and International Context (Ed. J. Jackson, M. Langer and P. Tillers), Oxford: Hart, 2008, pp. 65 y ss. Para Inglaterra ver: ASHWORTH, Andrew, Sentencing and Criminal Justice, London: Butterworths, 2000, especialmente pp. 17 y ss.

${ }^{97}$ MEDINA SCHULZ, "Sobre la determinación de pena", cit. nota $\mathrm{n}^{\circ}$ 3, p. 215. En el mismo sentido: MALDONADO FUENTES, Francisco, "Fundamentación y determinación de la pena en el Derecho Penal de adolescentes. A propósito del juicio seguido contra B.N.M. por delito de robo con intimidación (RUC 0900505404-1) en la V región", Revista Ius et Praxis, año 17, N² (2011), pp. 507 y ss.

${ }^{98}$ NEUMANN, Ulfried, Wahrheit im Recht. Zu Problematik und Legitimität einer fragwürdigen Denkform, Baden Baden: Nomos Verlag, 2004, pp. 53 y ss.
} 
NÚÑEZ, Raúl y VERA, Jaime, "Determinación judicial de la pena,

Motivación y su control en el Derecho penal de adolescentes chileno".

sino que debería ser discutida en la causal genérica o relativa de infracción al derecho que pasaremos a desarrollar a continuación.

\subsection{Infracción del derecho.}

En cuanto a la posibilidad de controvertir la fundamentación de la sentencia por la vía de la errónea aplicación del derecho con influencia substancial en lo dispositivo del fallo, existe un inconveniente impuesto por nuestra tradición jurisprudencia, presente desde la vigencia del antiguo recurso de casación y que ha sido abordado atinadamente por Medina. ${ }^{99}$ El mismo consiste en sostener que dado los amplios espacios de discrecionalidad con que cuenta el juez a la hora de individualizar la pena, la decisión que se adopte al respecto no estaría sujeta a revisiones por la vía de un recurso de derecho estricto como el de nulidad.

Por cierto esta tradición jurisprudencial resulta insostenible a luz de las consideraciones que han sido expuestas en este trabajo. Además, ha posibilitado que la decisión que se adopte, sea más bien el reflejo de las apreciaciones subjetivas sobre la justicia que pretenden expresar quienes resuelven, que el resultado de un trabajo de argumentación racional.

Más aún, esta tradición es la que ha permitido que a raíz de la decisión acerca del exacto contenido del injusto y culpabilidad del hecho, el juez, al momento de seleccionar la sanción, practique un ejercicio de aplicación directa de consideraciones político criminales, de sesgo preventivo (especialmente, preventivo general negativo) carentes de limitaciones impuestas a partir de un trabajo de reflexión dogmática.

Con todo, aquí no estamos en la hipótesis en que el órgano de adjudicación ignore su deber de fundamentación de la pena, sino que el razonamiento sobre la procedencia de un criterio o en la interpretación de éste, y sus consecuencias, se efectúa en un razonamiento jurídico erróneo o incorrecto.

Llegados a este punto la pregunta fundamental es: ¿cuándo se ha aplicado una norma erróneamente? Para nosotros, la respuesta no puede ser otra que: cuando se ha realizado incorrectamente el discurso de aplicación o adecuación por el órgano de adjudicación. El objetivo del discurso de aplicación será determinar cuál de las normas válidas en conflicto es la adecuada al caso concreto, una vez que éste ha sido descrito en sus aspectos relevantes. En efecto, sólo son objeto del discurso jurídico de aplicación las normas jurídicas válidas; y en relación a los diferentes problemas de justificación de las decisiones judiciales o de las normas jurídicas. En otras palabras, la adecuada aplicación de una norma jurídica (general) determina la justificación de la decisión judicial (la norma jurídica individual). ${ }^{100}$

En virtud de lo anterior, surge la conveniencia de vincular el sentido preciso de los criterios del artículo 24 de la LRPA, con las nociones de injusto, culpabilidad o con consideraciones preventivo especiales positivas, pues siempre que se exceda de aquel sentido, el sentenciador, irremediablemente, incurrirá en la causal de errónea aplicación con influencia

\footnotetext{
${ }^{99}$ MEDINA SCHULZ, "Sobre la determinación de pena”, cit. nota $n^{\circ}$ 3, p. 226.

${ }^{100}$ GÜNTHER, Klaus, “Critical Remarks on Alexy’s “Special-Case Thesis'”, Ratio Juris Nº 6 (1993), p. 155.
} 
Polít. crim. Vol. 7, № 13 (Julio 2012), Art. 5, pp. 168 - 208.

[http://www.politicacriminal.cl/Vol_07/n_13/Vol7N13A5.pdf]

substancial en lo dispositivo del fallo, pues producto de tal error, siempre se seleccionará una pena diversa de la que exigía la aplicación de las reglas del sistema.

Indudablemente, que una eventual errónea aplicación de los criterios previstos en el artículo 24 de la LRPA, estará siempre condicionada por las consideraciones que se extraigan de los hechos y circunstancias personales del menor infractor, que sean objeto de prueba durante el desarrollo del correspondiente juicio oral, o durante la audiencia de determinación de la pena, al extremo que es posible visualizar tantas infracciones como matices pueda aportar la casuística. No obstante ello, es posible plantear a priori, algunos supuestos en que evidentemente se producirá la infracción del criterio respectivo.

Tratándose del criterio de la gravedad del ilícito, puede producirse una errónea aplicación del mismo, cuando factores que incidan en una menor intensidad del injusto (desde la perspectiva objetiva, un menor riesgo creado en el momento ex ante y realizado en el momento ex post y desde la perspectiva subjetiva menor grado de imputación subjetiva, por menor intensidad en el conocimiento del riesgo creado), los cuales hayan sido acreditados durante el desarrollo del juicio, sean ponderados para la elección de una sanción que no sea menos severa del respectivo tramo.

A propósito del criterio de la edad del adolescente infractor, una aplicación de este criterio a partir del mero dato cronológico, como podría ser la elección de una sanción grave del respectivo tramo, por el sólo hecho que el menor esté próximo a enterar la mayoría de edad, prescindiendo de pruebas que den cuenta que a pesar de su edad cronológica, no presenta un desarrollo de sus competencias cognitivas y sociales coherente con su edad real.

En el caso del criterio de la idoneidad, se puede producir una errónea aplicación del mismo, siempre que se utilice en clave paternalista, a la usanza del antiguo sistema tutelar, es decir, como fundamento y no como límite de la imposición de la pena. En esta misma línea, se produce también la infracción, cuando a partir de consideraciones netamente peligrosistas, se pretende introducir factores retributivos o preventivos generales negativos a la luz de este criterio.

\section{Conclusiones.}

El deber de motivación de la sentencia constituye una garantía fundamental de todo tipo de procedimiento y particularmente del procedimiento penal, ámbito en el cual la decisión que se adopte por parte del operador jurídico debe ser el producto de un ejercicio argumentativo fundado en un proceso de reflexión racional. A tal extremo llega la importancia de esta garantía, que cuenta con pleno reconocimiento y consagración en el ordenamiento jurídico internacional, así como en la mayoría de las constituciones de los países que integran nuestro entorno cultural. La misma, además, se vincula directamente con la noción de debido proceso, entendido, este último en un sentido mucho más amplio que la mera consagración formal de la garantía del juicio previo en el artículo $19 \mathrm{~N}^{\circ} 3$ de la Constitución, integrado por un complejo haz de garantías. En este contexto la obligación de motivar las sentencias, se origina de la idea misma de la jurisdicción y de su ejercicio en los Estados democráticos, donde no pueden desligarse las ideas de jurisdicción y motivación: 
NÚÑEZ, Raúl y VERA, Jaime, "Determinación judicial de la pena, Motivación y su control en el Derecho penal de adolescentes chileno".

ésta es constitutiva de aquélla, de tal forma que la motivación no es algo obligatorio desde un punto de vista externo o formal, sino que es inherente a la aplicación de derecho.

El deber-garantía de motivación de las sentencias, impone no solamente la necesidad de señalar las razones por las cuales se da por establecido el hecho y la participación que sirve de base a la reacción penal, sino que alcanza también a la expresión del ejercicio reflexivo y racional que conduce a la imputación de las consecuencias jurídicas al autor del hecho, esto es, en el ámbito del derecho penal, particularmente, la pena. Para afirmar lo anterior, existe una sólida base normativa, tanto en la Constitución, como en los Códigos Penal y Procesal Penal, no obstante lo cual ha predominado en la jurisprudencia una cierta tendencia que, sin desconocer la garantía de la motivación, parte de la premisa que en cuanto a la imposición de la pena, constituye una labor de naturaleza discrecional y por lo mismo carente de limites formulados a partir de la elaboración dogmática. Esta circunstancia es la que muchas veces conduce a la adopción de decisiones arbitrarias en el ámbito de la individualización de la pena.

Con la entrada en vigencia de la LRPA, se ha establecido un nuevo sistema de responsabilidad para adolescentes infractores de la ley penal, que, junto con proponer un nuevo catálogo de sanciones, especiales para este tipo de criminalidad, ha contemplado un complejo sistema de individualización de las mismas. Este sistema, a pesar de carecer de autonomía, por remitir muchos de sus aspectos al sistema previsto en el Código Penal para los adultos, se caracteriza por entregar al sentenciador mayores espacios de decisión que el sistema de adultos, o si se quiere una mayor discrecionalidad en la aplicación de las diversas fases del sistema, especialmente, con motivo de la elección de la sanción a aplicar. Estos espacios de mayor flexibilidad, pueden ser el ámbito propicio para el surgimiento de decisiones que enarbolando la bandera de la discrecionalidad, devengan en sentencias definitivamente arbitrarias. Lo anterior es especialmente grave, cuando se trata del juzgamiento de menores, quienes de acuerdo con la nueva ley cuentan con un cúmulo de garantías, las cuales, entre otras cosas, imponen al operador jurídico la obligación de obrar conforme con su interés superior.

A fin de precaver la arbitrariedad en la toma de decisiones respecto la elección de la sanción de menores, la dogmática penal debe asumir un rol más activo, propendiendo al establecimiento de fronteras. Estas, se ven expresadas a la hora de precisar un sentido preciso de los criterios que deben iluminar la labor del juez que juzga a un menor infractor de la ley penal, esto es, los criterios previstos en el artículo 24 de la LRPA. A tales, no se les puede atribuir un contenido meramente discrecional, sino que el mismo se encuentra en directa conexión con consideraciones relativas al injusto del hecho (letras a, b, c y e) con aspectos de culpabilidad e imputación personal (letra e) o con las consideraciones preventivo especiales positivas que inspiran y limitan al sistema (letra f). A partir de la definición de este sentido, es posible extraer grupos de supuestos, que a partir de un desarrollo jurisprudencial más profuso, posibilitarán la formulación de una suma de criterios racionales, que, a su vez conduzcan a una mayor estandarización de las decisiones que se adopten. 
Polít. crim. Vol. 7, № 13 (Julio 2012), Art. 5, pp. 168 - 208.

[http://www.politicacriminal.cl/Vol_07/n_13/Vol7N13A5.pdf]

Frente a las irregularidades en que incurran los tribunales respecto del cumplimiento del deber de motivación de la pena impuesta en procesos atingentes a adolescentes infractores, ya sea por la ausencia de fundamentación, o por la equivocada interpretación de la normas y criterios del sistema, el recurso de nulidad, tanto en la causal de falta de fundamentación, como de errónea aplicación del derecho, se erige como el mecanismo idóneo para restablecer la plena vigencia del deber-garantía de motivación de la sentencia.

\section{BIBLIOGRAFÍA}

ALEXY, Robert, Teoría de la argumentación jurídica, Madrid: Centro de Estudios Constitucionales, 1997.

ALISTE SANTOS, Tomás-Javier, La motivación de las resoluciones judiciales, Madrid: Marcial Pons, 2011.

ANDRÉS IBÁÑEZ, Perfecto, Justicia penal, derechos y garantías, Lima: Palestra, 2007.

ASHWORTH, Andrew, Sentencing and Criminal Justice, London: Butterworths, 2000.

AYO FERNÁNDEZ, Manuel, Las garantías del menor infractor, Navarra: Aranzadi, 2004.

BELL, John, Judiciaries within Europe. A Comparative Review, Cambridge: CUP, 2006.

BELOFF, Mary, "Algunas confusiones en torno a las consecuencias jurídicas de la conducta transgresora de la ley penal en los nuevos sistemas de justicia juvenil latinoamericanos", en: GARCÍA MENDEZ, Emilio (Comp.), Adolescentes y responsabilidad penal, Buenos Aires: Ad Hoc, 2001.

BERRÍOS DÍAZ, Gonzalo, "El nuevo sistema de justicia penal para adolescentes", Revista de estudios de la justicia $\mathrm{N}^{\mathrm{o}} 6$ (2005).

BESIO HERNÁNDEZ, Martín, Los criterios legales y judiciales de individualización de la pena, Valencia: Tirant lo Blanch, 2011.

BORDALÍ SALAMANCA, Andrés, "El debido proceso civil", en: VV.AA., $L a$ constitucionalización del derecho chileno, Santiago: Editorial Jurídica de Chile, 2003.

BUNG, Jochen, Subsumtion und Interpretation, Baden-Baden: Nomos, 2003.

BUSTOS RAMÍREZ, Juan, Derecho penal del niño-adolescente (estudio de la Ley de Responsabilidad Penal del Adolescente), Santiago: Ediciones Jurídicas de Santiago, 2007.

CEA EGAÑA, José Luis, Tratado de la Constitución del 1980. Características generales, garantías constitucionales, Santiago: Editorial Jurídica de Chile, 1988.

CERDA, Mónica y CERDA, Rodrigo, Sistema de responsabilidad penal para adolescentes, Santiago: Librotecnia, 2006.

CILLERO BRUÑOL, Miguel, Consideraciones para la aplicación del criterio de idoneidad en la determinación de las sanciones en el Derecho Penal de adolescentes chileno, Documento de Trabajo N ${ }^{\circ}$, Unidad de Defensa Penal Juvenil, Defensoría Penal Pública, año 2008.

, "Ley N 20.084 sobre Responsabilidad Penal de Adolescentes", Anuario de Derechos Humanos, № 2 (2006). 
NÚÑEZ, Raúl y VERA, Jaime, "Determinación judicial de la pena,

Motivación y su control en el Derecho penal de adolescentes chileno".

, "Nulla poena sine culpa. Un límite necesario al castigo penal de los adolescentes", en: Adolescentes y responsabilidad penal, Buenos Aires: Ad Hoc, 2001.

Derechos del Niño", en http://www.observatoriosocial.com.ar/proyectos/proelinteres.pdf

COLOMBO CAMPBELL, Juan, El debido proceso constitucional, Ciudad de México: Porrúa, 2007.

COLOMER HERNÁNDEZ, Ignacio, La motivación de las sentencias: Sus exigencias constitucionales y legales, Valencia: Tirant lo Blanch, 2003.

COMOGLIO, Luigi Paolo, Etica e técnica del "giusto processo”, G. Giappichelli Editores, Torino, 2004.

CORTEZ MATCOVICH, Gonzalo, El recurso de nulidad. Doctrina y jurisprudencia, LexisNexis: Santiago, 2006.

COUSO SALAS, Jaime, "Comentario al artículo 69", Código Penal comentado. Parte general. Doctrina y jurisprudencia, COUSO, J. y HERNÁNDEZ, H. (Dirs.), Abelodo Perrot: Santiago, 2011.

, "Principio educativo y (re)socialización en el Derecho penal juvenil", Justicia y Derechos del Niño, No 8 (2006), UNICEF, Santiago.

DE ASÍS ROIG, Rafael, El Juez y la motivación en el Derecho, Dykinson: Madrid, 2005.

DELGADO DEL RINCÓN, Luis Esteban, Constitución, Poder Judicial y responsabilidad, Madrid: Centro de Estudios Constitucionales, 2002.

DEMETRIO CRESPO, Eduardo, Prevención general e individualización judicial de la pena, Salamanca: Ediciones Universidad de Salamanca, 1999.

DÍAZ CANTÓN, Fernando, La motivación de la sentencia penal y otros estudios, Buenos Aires: Editores del Puerto, 2005.

DÍEZ-PICAZO GIMÉNEZ, Ignacio, Poder Judicial y responsabilidad. Madrid: La Ley, 1993.

DO AMARAL E SILVA, Antonio Fernando, "La protección como pretexto para el control social arbitrario de los adolescentes o la supervivencia de la doctrina de la situación irregular", Adolescentes y responsabilidad penal, Buenos Aires: Ad Hoc, 2001.

ESPARZA LEIBAR, Iñaki, El principio del proceso debido, Barcelona: JM. Bosch, 1995.

ETCHEBERRY, Alfredo, Derecho Penal. Parte general (tomo II), Santiago: Editorial Jurídica de Chile, 1998.

FERRAJOLI, Luigi, Derecho y razón. Teoría del garantismo penal, Madrid: Trotta, 1995.

FERRUA, Paolo, Il "giusto processo", Bologna: Zanichelli, 2005.

GONZÁLEZ CUSSAC y CUERDA ARNAU, "Derecho Penal de menores: criterios generales de aplicación de las medidas", GONZÁLEZ CUSSAC/ TAMARITSUMALLA/GÓMEZ COLOMER (coord.), Justicia penal de menores y jóvenes, Valencia: Tirant lo Blanch, 2002.

GÜNTHER, Klaus, Der Sinn für Angemessenheit. Anwendungsdiskurse in Moral und Recht, Suhrkamp Verlag, Frankfurt, 1988. , "Critical Remarks on Alexy's "Special-Case Thesis"”, Ratio Juris $\mathrm{N}^{\circ}$ $6(1993)$.

"Un concepto normativo de coherencia para una teoría de la argumentación jurídica”, Doxa № 17-18 (1995). 
Polít. crim. Vol. 7, № 13 (Julio 2012), Art. 5, pp. 168 - 208.

[http://www.politicacriminal.cl/Vol_07/n_13/Vol7N13A5.pdf]

, Schuld und Kommunikative Freiheit, Frankfurt: Klostermann, 2005.

HÄBERLE, Peter, La libertad fundamental en el Estado Constitucional, Granada: Comares, 2003.

HABERMAS, Jürgen, Theorie des kommunikativen Handelns, Band II, Frankfurt: Suhrkamp, 1981.

, Faktizität und Geltung, Frankfurt: Suhrkamp, 1998

HELMHOLZ, RH.; GRAY, Charles M.; LANGBEIN, John H.; MOGLEN, Eben; SMITH, Henry E.; y, ALSCHULER, Albert W., The Privilege Against Self-Incrimination, Chicago: The University of Chicago Press, 1997.

HERNÁNDEZ BASUALTO, Héctor, "El nuevo Derecho penal de adolescentes y la necesaria revisión de su teoría del delito", Revista de Derecho, Universidad Austral, vol. XX, N² (2007).

HIGUERA GUIMERÁ, Juan, Derecho penal juvenil, Barcelona: Editorial Bosch, 2003.

HORVITZ LENNON, María Inés, "Determinación de las sanciones en la ley responsabilidad penal juvenil y procedimiento aplicable", Revista de estudios de la justicia, $\mathrm{N}^{\circ} 7$ (2006).

IACOVIELLO, Francesco, La motivazione della sentenza peale e il suo controllo in cassazione, Milano: Giuffre, 1997.

IGARTUA SALAVERRIA, Juan, La motivación de las sentencias, imperativo constitucional, Madrid: Centro de Estudios Políticos y Constitucionales, 2003. , El razonamiento en las resoluciones judiciales,

Lima: Palestra, 2009.

ITURRALDE SESMA, Victoria, Aplicación del Derecho y justificación de la decisión judicial, Valencia: Tirant lo Blanch, 2003.

JESCHECK, Hans - Heinrich, Tratado de derecho penal. Parte general, Granada: Comares, 2002.

KINDHÄUSER, Urs, Strafprozessrecht, Baden-Baden: Nomos, 2006.

LAGODNY, Otto, Strafrechtvor den Schranken der Grundrecht, Tübingen: Mohr, 1996.

LÓPEZ MASLE, Julián, "Debido Proceso en Chile: hacia un principio generador de reglas", en: BORDALÍ, Andrés (Coord.), Justicia Constitucional y Derechos Fundamentales. Universidad Austral de Chile, Santiago: Editorial LexisNexis, 2006.

MAIER, Julio BJ., Derecho procesal penal. Fundamentos, tomo I, Buenos Aires: Editores del puerto, 1996.

MALDONADO FUENTES, Francisco, "Fundamentación y determinación de la pena en el Derecho Penal de adolescentes. A propósito del juicio seguido contra B.N.M. por delito de robo con intimidación (RUC 0900505404-1) en la V región”, Revista Ius et Praxis, año 17, $\mathrm{N}^{\circ} 2$ (2011).

MATUS ACUÑA, Jean Pierre, "Proposiciones respecto de las cuestiones no resueltas por la Ley $\mathrm{N}^{\circ} 20.084$ en materia de acumulación y orden de cumplimento de las penas", Revista ius et praxis, Vol. 14, № 2, (2008).

MEDINA SCHULZ, Gonzalo, "Sobre la determinación de pena y el recurso de nulidad en la ley 20.084 sobre responsabilidad penal adolescente", Revista de estudios de la justicia, $\mathrm{N}^{\circ} 11$ (2009).

MIR PUIG, Santiago, Derecho Penal. Parte General (7 edición) Barcelona: Editorial Reppertor, 2004. 
NÚÑEZ, Raúl y VERA, Jaime, "Determinación judicial de la pena,

Motivación y su control en el Derecho penal de adolescentes chileno".

MONTERO AROCA, Juan, Independencia y responsabilidad del juez, Madrid: Civitas, 1990.

NEUMANN, Ulfried, Wahrheit im Recht. Zu Problematik und Legitimität einer fragwürdigen Denkform, Baden-Baden: Nomos Verlag, 2004.

NÚÑEZ OJEDA, Raúl, "El sistema de recursos procesales en el ámbito civil en un Estado democrático deliberativo", Ius et Praxis, $\mathrm{N}^{\circ} 1$, año 14 (2008).

PASTOR, Daniel, "El deber judicial de motivar las condenas", en: VV.AA., Reflexiones sobre el procedimiento penal. Una tarde con Julio Maier”, Buenos Aires: Editorial Ad-Hoc, 2010.

PIZZI, William, "Sentencing in US: An Inquisitorial Soul in an Adversarial Body?", Crime, Procedure and Evidence in a Comparative and International Context (Ed. J. Jackson, M. Langer and P. Tillers), Oxford: Hart, 2008.

REDLICH, Norman; ATTANASIO, John; y, GOLDSTEIN, Joel K, Understanding Constitutional Law, New York: LexisNexis, 2005.

RIEUTORD ALVARADO, Andrés, El recurso de nulidad en el nuevo proceso penal, Santiago: Editorial Jurídica de Chile, 2007.

RIVACOBA y RIVACOBA, Manuel, "Las circunstancias modificativas de la responsabilidad criminal en la teoría general del delito", Revista doctrina penal, año 11, $\mathrm{N}^{\circ} 43$ (1988).

RODRÍGUEZ BOENTE, Sonia Esperanza, La justificación de las decisiones judiciales, Universidad de Santiago de Compostela, 2003.

ROGALL, Klaus, Der Beschuldigte als Beweismittel gegen sich selbst, Berlin: Duncker und Humblot, 1977.

ROXIN, Claus, Derecho procesal penal, Buenos Aires: Editores del Puerto, 2000. , "Prevención y determinación de la pena", Fundamentos político-criminales del Derecho penal, Buenos Aires: Hammurabi, 2008.

RUDNIK VIZCARRA, Carolina, La compensación racional de circunstancias modificatorias en la determinación judicial de la pena, Santiago: Legal publishing, 2007.

SILVA SÁNCHEZ, Jesús María, "La teoría de la determinación de la pena como sistema (dogmático): un primer esbozo", In Dret, $\mathrm{N}^{\circ} 2$ (2007) (Disponible en: http://www.indret.com/pdf/426 es.pdf).

TAVOLARI OLIVEROS, Raúl, "El proceso civil chileno: Una lectura desde el debido proceso y la eficacia de la jurisdicción, de cara a la reforma", en: EL MISMO, Tribunales, jurisdicción y proceso, Santiago: Editorial Jurídica de Chile, 1994.

TARUFFO, MICHELE, "La motivación de la sentencia", Páginas sobre justicia civil, Madrid: Marcial Pons, 2009.

, La motivación de la sentencia civil, Madrid: Trotta, 2011.

TORO JUSTINIANO, Constanza María F., El debido proceso penal, Santiago: Ediciones Jurídicas de Santiago, 2009.

VAN WEEZEL, Alex, "Determinación de la Pena Exacta: El Artículo 69 del Código Penal", Ius et Praxis [online]. vol.7, № 2 (2001) [citado 2012-03-08], pp. 401-407. Disponible en: $<$ http://www.scielo.cl/scielo.php?script=sci_arttext\&pid=S071800122001000200017\&lng=es\&nrm=iso>. ISSN 0718-0012.doi: 10.4067/S071800122001000200017. 
Polít. crim. Vol. 7, № 13 (Julio 2012), Art. 5, pp. 168 - 208.

[http://www.politicacriminal.cl/Vol_07/n_13/Vol7N13A5.pdf]

VERREL, Torsten, Die Selbsbelastungsfreiheit im Strafverfahren, München, CH. Beck, 2001.

ZIFFER, Patricia, "Consideraciones acerca de problemática de la individualización de la pena" en: MAIER, Julio (Comp.) Determinación judicial de la pena, Buenos Aires: Editores del Puerto, 1993.

, Lineamientos de la determinación de la pena, Buenos Aires, Ad-Hoc, 1996. 